\title{
EFFECT OF OXYGEN-LIMITING TIDAL CONDITIONS ON MUSCLE METABOLISM AND STRUCTURE IN THE GIANT ACORN BARNACLE, BALANUS NUBILUS
}

\author{
A Thesis \\ presented to \\ the Faculty of California Polytechnic State University, \\ San Luis Obispo
}

\author{
In Partial Fulfillment \\ of the Requirements of the Degree \\ Master of Science in Biological Sciences
}

by

Katie O Grady

December 2016 
(C) 2016

Katie O Grady

ALL RIGHTS RESERVED 
TITLE:

AUTHOR:

DATE SUBMITTED:

COMMITTEE CHAIR:

COMMITTEE MEMBER:

COMMITTEE MEMBER:
Effect of Oxygen-Limiting Tidal Conditions on Muscle Metabolism and Structure in the Giant Acorn Barnacle, Balanus nubilus

Katie O Grady

December 2016
Kristin Hardy, Ph.D.

Assistant Professor of Biological Sciences

Jason Blank, Ph.D.

Associate Professor of Biological Sciences

Nikki Adams, Ph.D.

Professor of Biological Sciences 


\author{
ABSTRACT \\ Effect of Oxygen-Limiting Tidal Conditions on \\ Muscle Metabolism and Structure in the \\ Giant Acorn Barnacle, Balanus nubilus
}

Katie O Grady

Crustacean muscle fibers are some of the largest cells in the animal kingdom, with fiber diameters in the giant acorn barnacle (Balanus nubilus) exceeding 3 $\mathrm{mm}$. Sessile animals with extreme muscle sizes and that live in the hypoxiainducing intertidal zone - like $B$. nubilus - represent ideal models for probing the effects of oxygen limitation on muscle cells. We investigated changes in metabolism and structure of $B$. nubilus muscle in response to: normoxic immersion, anoxic immersion, or air emersion, for acute (6h) or chronic (6h exposures twice daily for $2 \mathrm{wks}$ ) time periods. Following exposure, we immediately measured hemolymph $\mathrm{pO}_{2}, \mathrm{pCO}_{2}, \mathrm{pH}, \mathrm{Na}^{+}, \mathrm{Cl}^{-}, \mathrm{K}^{+}$, and $\mathrm{Ca}^{+}$then excised tergal depressor (TD) and scutal adductor (SA) muscles to determine citrate synthase (CS) activity, lactate dehydrogenase (LDH) activity, and Dlactate levels. We also prepared a subset of SA and TD muscles from the chronic barnacles for histological analysis of fiber diameter (Feret's), cross-sectional area (CSA), mitochondrial distribution and relative density, as well as nuclear distribution and myonuclear domain size. There was a significant decrease in hemolymph $\mathrm{pO}_{2}$ and $\mathrm{pCO}_{2}$ following acute and chronic anoxic immersion, whereas air emersion $\mathrm{pO}_{2}$ and $\mathrm{pCO}_{2}$ was comparable to normoxic levels. Fiber CSA and diameter did not change significantly in either tissue, while myonuclear domain size in SA muscle was significantly lower in the anoxic and emersion groups than the normoxic control. Neither CS, nor LDH activity, showed any significant treatment effect in either tissue, whereas both muscles had significantly higher D-lactate levels after air emersion following acute (though not chronic) exposure. Thus far, our findings indicate that $B$. nubilus experience a general reduction in aerobic metabolism under anoxia, emersion is only mildly oxygen-limiting, and that muscle plasticity is occurring during chronic emersion and anoxia.

Keywords: Balanus nubilus, giant barnacle, anoxia, hypoxia, giant muscle cells, intertidal, metabolism, muscle plasticity, histology 


\section{ACKNOWLEDGMENTS}

I would like to thank the Cal Poly Extramural Funding Initiative (EFI), CSU's COAST, the Cal Poly Biological Sciences Department and the Herbst Foundation for their generous funding. This research would not have been possible without the ingenious technical support of Rob and Doug Brewster as well as the engineering expertise of John Gerrity. In addition, I would like to thank Tom Moylan, Jason Felton, and Jacob Gerhardt for their experimental support at the Cal Poly research pier. I want to acknowledge support from the NOAA IOOS program through CeNCOOS for the temperature data collected at the Cal Poly

Pier (grant to R. Walter and D. Wendt, Cal Poly). Thank you to the following Cal Poly research divers for joining me in the physically demanding job of collecting acorn barnacles: Grant Waltz, Michaela Hoffman, Paul Carvalho, Kaitlin Johnson, Jason Felton, Katherine Rodriguez, Eric Anderson, Maurice Goodman, Maggie Jenkins, Megan Wilson, Emily Spurgeon, Nicole Hack, and Bridget Benson. Thank you to Alice Bourgeon, Emily Resner, Bri Belanger, Katie Cornella, Laura Clayton, Danielle Zezoff, Nate Gilbreth, Maya Katz, Alex Westman, and Griffin Capehart for helping with animal dissections, laboratory experiments and sample processing.

I would like to extend a special thanks to my family and friends who have shown a genuine interest in my research. Lastly, I would like to thank Dr. Kristin Hardy, Dr. Sean Lema, Courtney Hart, Kaitlin Johnson and Emily Resner for your support and for creating a warm, collaborative lab atmosphere. My advisor, Dr. 
Kristin Hardy, is exceptionally passionate about our work with Balanus nubilus and her contagious energy was never short of inspiring. She is a truly phenomenal teacher and research scientist. This work would not have been remotely possible without her countless hours of involvement and guidance. 


\section{TABLE OF CONTENTS}

LIST OF TABLES.

LIST OF FIGURES.

CHAPTER

1. INTRODUCTION ................................................. 1

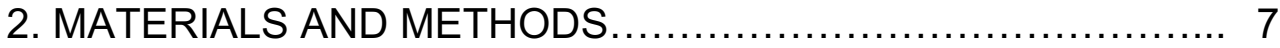

2.1 Test Organisms........................................ 7

2.1.1 Animal Care, Maintenance and Preparation..... 7

2.2 Exposure Conditions and Experimental Design........... 7

2.2.1 Acute Experimental Protocol.................... 7

2.2.2 Chronic Experimental Protocol.................. 9

2.3 Hemolymph Gas and Electrolyte Measurements......... 10

2.4 Enzyme and D-lactate Assays........................... 11

2.5 Histology .............................................. 12

2.6 Statistical Analyses.................................... 15

3. RESULTS ...................................................... 17

3.1 Hemolymph Gas and Electrolytes...................... 17

3.2 Enzyme Activity and D-lactate......................... 18

3.3 Histology ............................................... 20

4. DISCUSSION ................................................ 22

4.1 Muscle Characterization.............................. 22

4.2 Hemolymph Gas and Electrolytes....................... 25

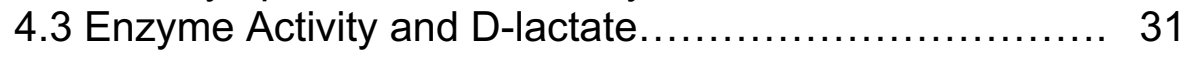

4.4 Structural Plasticity.................................... 36

4.5 Summary ............................................... 37

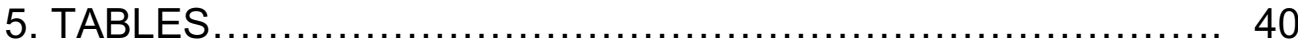

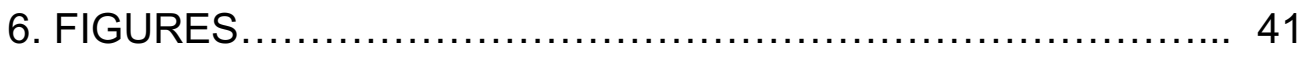

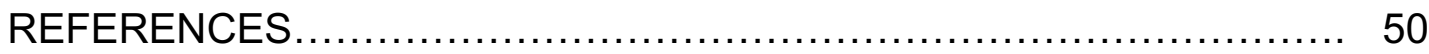




\section{LIST OF TABLES}

Tables

Page

1. Concentration (mM) of $\mathrm{Na}^{+}, \mathrm{Cl}^{-}, \mathrm{K}^{+}$and $\mathrm{Ca}^{2+}$ in $B$. nubilus hemolymph following exposure to normoxic immersion, air emersion, and anoxic immersion. Means with different letters are significantly different (post-hoc Tukey's HSD, $\alpha=0.05$ ). Values are means \pm SEM, $n=9$ barnacles per treatment group (except chronic $\left[\mathrm{Na}^{+}\right]$and $\left[\mathrm{Cl}^{-}\right], \mathrm{n}=3$ per treatment group)...... 40 


\section{LIST OF FIGURES}

Figures

Page

1. Giant acorn barnacle, Balanus nubilus. (A) Lateral view of giant muscle fibers (red arrows), and (B) apical view to scale of Balanus nubilus.

2. Chronic exposure regime for $B$. nubilus. For two weeks barnacles were exposed twice daily for $6 \mathrm{~h}$ (6:00-12:00 and 18:00-24:00) to one of the following oxygen-limiting tidal conditions: normoxic immersion (bubbled with atmospheric air; control), anoxic immersion (bubbled with pure nitrogen gas) and air emersion (exposed to the air). Barnacle tissues were sampled immediately at the end of final $6 \mathrm{~h}$ exposure period (12:00 on the $14^{\text {th }}$ day of experimentation).

3. Hemolymph $(\mathrm{A}, \mathrm{B}) \mathrm{pO}_{2}(\mathrm{mmHg}),(\mathrm{C}, \mathrm{D}) \mathrm{pCO}_{2}(\mathrm{mmHg})$ and $(\mathrm{E}, \mathrm{F}) \mathrm{pH}$ in $B$. nubilus following acute (left panel) and chronic (right panel) exposure to normoxic immersion $(N)$, air emersion $(E)$ and anoxic immersion $(A)$. Columns with different letters are significantly different (post-hoc Tukey's HSD test). Values are means \pm SEM, $n=8-9$ barnacles per treatment group

4. Negative linear relationship between $\mathrm{pCO}_{2}$ and $\mathrm{pH}$ following both $(A)$ acute and $(B)$ chronic exposure to oxygen-limiting tidal conditions. Each data point represents the average hemolymph $\mathrm{pCO}_{2}$ and $\mathrm{pH}$ value from an individual barnacle taken at the end of the exposure period, and includes measurements from barnacles across all three treatments $(\mathrm{N}=27)$.

5. Enzyme activity (U mg-1 protein) for (A,B) CS and (C,D) LDH in $B$. nubilus scutal adductor (black) and tergal depressor (white) muscles following acute (left panel) and chronic (right panel) exposure to normoxic immersion $(\mathrm{N})$, air emersion $(\mathrm{E})$ and anoxic immersion $(\mathrm{A})$. Within each tissue, columns with different letters are significantly different (post-hoc Tukey's HSD test). Asterisks indicate means that are significantly different between muscle types in the $\mathrm{N}$ (control) treatment group (student's t-test). Values are means \pm SEM, $n=9$ (acute) and $n=12$ (chronic) barnacles per treatment group 
6. D-lactate concentration ( $\mathrm{mM})$ in B. nubilus scutal adductor (black) and tergal depressor (white) muscles following (A) acute and (B) chronic exposure to normoxic immersion $(\mathrm{N})$, air emersion $(\mathrm{E})$ and anoxic immersion (A). Within each tissue, columns with different letters are significantly different (post-hoc Tukey's HSD test). Asterisks indicate means that are significantly different between muscle types in the $\mathrm{N}$ (control) treatment group (student's t-test). Values are means \pm SEM, $n=9$ (acute) and 12 (chronic) barnacles per treatment group

7. The (A) Feret's diameter $(\mu \mathrm{m})$, (B) cross-sectional area $\left(\mu \mathrm{m}^{2}\right)$, and (C) myonuclear domain $\left(\mu \mathrm{m}^{3} /\right.$ nuclei) in $B$. nubilus scutal adductor (black) and tergal depressor (white) muscles following chronic (2wk) exposure to normoxic immersion $(\mathrm{N})$, air emersion $(\mathrm{E})$ and anoxic immersion (A). Within each tissue, columns with different letters are significantly different (post-hoc Tukey's HSD test). Asterisks indicate means that are significantly different between muscle types from the same treatment group (paired t-test). Values are means \pm SEM, $n=15$ fibers (from $n=3$ barnacles) per treatment group for CSA and diameter, $\mathrm{n}=10-15$ fibers (from $n=2-3$ barnacles) per treatment group for myonuclear domain.

8. Representative images of succinic dehydrogenase $(\mathrm{SDH}$; mitochondrial stain) stained muscle fiber cross-sections $(30 \mu \mathrm{m})$ from $B$. nubilus $(A, B)$ TD and (C,D) SA muscles. (E,F) Rat plantaris muscle that was sectioned $(30 \mu \mathrm{m})$, stained and imaged directly alongside the barnacle muscle to allow direct comparison of relative mitochondrial fractional volume (as indicated by staining intensity). Note the extremely low SDH staining intensity in both the TD and SA muscles compared to the rat muscles imaged under the same exposure conditions. Scale bar $=200 \mu \mathrm{m}(\mathrm{A}, \mathrm{C}, \mathrm{E})$ and $80 \mu \mathrm{m}(\mathrm{B}, \mathrm{D}, \mathrm{F})$

9. Representative images of $B$. nubilus $(A, C)$ scutal adductor and $(B, D)$ tergal depressor muscle fiber cross-sections $(12 \mu \mathrm{m})$ stained with DAPI (nuclear stain; $A, B$ ) and fluorescein conjugated-wheat germ agglutinin (WGA; sarcolemmal stain; C,D). Note the presence of subsarcolemmal and intermyofibrillar myonuclei, as well as the prominent fiber subdivision indicated by green-fluorescent WGA staining. Scale bar = $200 \mu \mathrm{m}$ 


\section{INTRODUCTION}

Barnacles (Cirripedia) routinely attract the attention of scientists in areas of classic ecology, reproduction, larval development and metamorphosis. Until recently, however, work pertaining to morphology and physiology in cirripedes was largely neglected due to the extensive work of Charles Darwin during the $17^{\text {th }}$ century (Anderson, 1994). Revisiting this area of study opens up a great number of interesting questions related to barnacle muscle function, respiratory physiology, functional diversity and evolution. As with other crustaceans, barnacles exhibit an elaborate musculature and, in some cases, their muscle fibers are among the largest cells in the animal kingdom. Whereas the skeletal muscle fibers of most organisms obtain a maximum diameter of $10-100 \mu \mathrm{m}$, hypertrophic fiber growth associated with post-metamorphic development can lead to fibers that are several hundred microns in diameter in certain fishes and crustaceans ( Jahromi and Atwood, 1971; Hoyle, 1987; Weatherley and Gill, 1987; Boyle et al., 2003; Johnson et al., 2004; Kinsey et al., 2007; Jimenez et al., 2008; Hardy et al., 2009; Hardy et al., 2010; Jimenez et al., 2011;).

Perhaps the most extreme case of such fiber growth is in the giant acorn barnacle, Balanus nubilus, which possess muscle fibers in adult specimens that can exceed $3 \mathrm{~mm}$ in diameter (Anderson, 1994). As a rule, small fiber sizes are thought to facilitate high rates of aerobic metabolism owing to short intracellular diffusion distances and high surface area to volume ratios (SA:V), both of which should facilitate adequate oxygen delivery to mitochondria in the cell. Despite these presumptive limitations, reaction-diffusion mathematical models have 
shown us that aerobic metabolic processes in organisms with 'extreme' muscle dimensions are not greatly limited by diffusion, though they do seem to operate on the brink of substantial diffusion limitation ( Kinsey et al., 2005; Kinsey et al., 2007; Jimenez et al., 2008; Locke \& Kinsey, 2008; Hardy et al., 2009;). Where the influence of diffusion can be demonstrated in these cells, however, is in the significant metabolic and structural reorganization that occurs during fiber growth in an effort to avoid diffusion limitations (Jimenez et al., 2008; Hardy et al., 2009; Kinsey et al., 2011).

The giant swimming muscles of the blue crab, Callinectes sapidus, provide an excellent example of such a hypertrophy-induced cellular restructuring (Hardy et al., 2009). In this species, muscle fiber size and therefore intracellular diffusion distances increase hypertrophically from the juvenile to adult stage. Subsequent restructuring of nuclear and mitochondrial distribution occurs evidently in response to diffusion constraints. In the anaerobic light fibers mitochondria are evenly distributed throughout the small fibers of juveniles, but in the large fibers of adults they are located almost exclusively on the edge where $\mathrm{O}_{2}$ concentrations are high. Nuclei have the inverse pattern: they are distributed peripherally in small fibers but are evenly distributed across the large fibers. The aerobic dark fibers, on the other hand, circumvent diffusion constraints associated with aerobic metabolism by creating distinct metabolic functional units within a single fiber via an intricate network of subdivisions, each complete with its own mitochondria, nuclei, and perfusions, though contraction apparently remains at the functional level of the whole fiber (Hardy et al., 2009; Kinsey et al., 
2011).This creates high SA:V and short diffusion distances needed to meet the high ATP turnover demands of sustained, oxidative contraction (Hardy et al., 2009).

B. nubilus represents a particularly unique model for further probing the influence of oxygen diffusion on aerobic metabolism and structural organization in muscle owing simply to the sheer magnitude of fiber hypertrophy that occurs in this species. It seems plausible that their aerobic ATP turnover rates could, in fact, be limited by such extreme diffusion distances, despite evidence to the contrary in so many other giant, but significantly smaller, muscle fibers (Kinsey et al., 2011). The giant acorn barnacle become increasingly more interesting as a study species when considering the additional fact that they lack a respiratory binding pigment (e.g., hemoglobin or hemocyanin); a trait that could greatly diminish the oxygen carrying capacity of their hemolymph (Terwilliger and Ryan, 2001; Waite and Walker, 1988). For reference, hemoglobin-less Antarctic Notothenioids have an arterial oxygen content that is approximately $10 \%$ of that in closely related red-blooded Notothenioids ( Holeton, 1974; Egginton, 1994). Moreover, $B$. nubilus is a sessile organism that is forcibly subject to the environmental conditions of its habitat, which includes low oxygen. This species is dominant in the subtidal and low intertidal zones. Thus, individuals may be subject to periodic hypoxia resulting from air emersion during low tide (Anderson, 1994; Davenport and Irwin, 2003; López et al., 2003) Nearshore eutrophication along the Pacific west coast are also increasing the occurrence of local hypoxic and anoxic dead zones (Grantham et al., 2004; Spicer, 2014). Multiple field 
studies on fish and crustaceans illustrate the detrimental effects of reduced oxygen saturation on larval settlement, biomass, growth, metabolism and behavior, but very few studies detail these effects on muscle structure and function (Gray et al., 2002).

When environmental conditions are suboptimal, B. nubilus forces together two pairs of movable calcified opercular plates, the scuta and the terga, to close the opening at the apex of its cone (Anderson, 1994). As a consequence of this protection, feeding rates decrease and subsequently gas exchange (e.g., oxygen) becomes more challenging (Desai and Prakash, 2009). Thus, the internal environment of acorn barnacles may become hypoxic, or eventually entirely anoxic (Davenport and Irwin, 2003). Opercular closure is predominantly mediated by the contraction of the scutal adductor (SA) muscle, which pulls together the two scutal plates. This feat is mechanically aided by the tergal depressor (TD) muscle, which is involved in depression of the operculum into the body cavity during closure (Anderson, 1994). Thus, the SA and TD muscles undergo extended periods of sustained contraction when the internal oxygen levels are likely to be limited. Both muscle groups are comprised of 'giant' fibers, which are striated, and yet share ultrastructural characteristics similar to vertebrate smooth muscle (Hoyle, 1987). We hypothesize that the giant SA and TD fibers of $B$. nubilus may have inherent differences in their fiber size, biochemical properties, and structural organization as a result of their distinct functional needs. We further predict that their responses to environmental hypoxia, or environmentally-induced internal hypoxia, are likely to differ. 
Physiological responses to hypoxia are sparsely documented for barnacles (Davenport and Irwin, 2003; Lopez et al., 2003; Desai and Prakash, 2009; Spicer, 2013), and virtually no studies exist that specifically address their muscle physiology under low oxygen conditions. We do know that during hypoxia, crustaceans commonly experience changes in the concentration and activity of certain key enzymes (Lopez et al., 2003; Desai and Prakash, 2009), an overall metabolic depression (Murdoch and Shumway, 1980; Castro et al., 2001), and an extensive reliance on anaerobic metabolism with consequent lactate accumulation (Burke, 1979; Castro et al., 2001; López et al., 2003). A high degree of skeletal muscle plasticity has also been documented during hypoxia in other fish and invertebrates; these include changes in mitochondrial density (Jimenez et al., 2008; Hardy et al., 2009) and enzyme/metabolite levels (Johnston and Bernard, 1982; Mykles, 1997). We would, therefore, expect to see similar modes of plasticity occurring in giant muscle fibers of $B$. nubilus in response to fluctuating environmental or internal oxygen.

In the current study, we aimed to 1) characterize the giant SA and TD muscle fibers of $B$. nubilus, and 2) investigate the metabolic and structural response of these fibers to acute (6h) and chronic (2wk) oxygen-limiting tidal conditions (i.e., normoxic immersion, anoxic immersion, air emersion). To this end, we determined the fiber diameter, fiber cross-sectional area, nuclear distribution, myonuclear domain size, lactate concentration, citrate synthase activity and lactate dehydrogenase activity from $B$. nubilus SA and TD muscles following acute and chronic exposure to normal or low oxygen conditions, as 
described above. Additionally, we sought to 3 ) describe the changes in hemolymph parameters $\left[\mathrm{pO}_{2}, \mathrm{pCO}, \mathrm{pH}\right.$, and electrolyte levels $\left(\mathrm{Na}^{+}, \mathrm{Cl}, \mathrm{K}^{+}\right.$, $\left.\left(\mathrm{Ca}^{2+}\right)\right]$ that occurred following the same bouts of acute and chronic low oxygen conditions. We hypothesize that hemolymph gas and electrolytes, muscle tissue enzyme activity (CS, LDH), D-lactate, fiber dimensions, and myonuclear domain in $B$. nubilus will change in response to acute and chronic exposure to air emersion and anoxic immersion. Understanding the physiological strategies used by $B$. nubilus for survival in low oxygen environments is vital to understanding the potential extent of their colonization in intertidal areas where oxygen availability is expected to decrease. More importantly, however, we hope to shed light on the anatomical features and metabolic strategies by which $B$. nubilus achieves and maintains adequate muscle function given the constraints of excessive intracellular diffusion distances, the lack of a respiratory binding pigment, and exposure to environmentally-induced low oxygen levels. 


\section{MATERIALS AND METHODS}

\subsection{Test Organisms}

\subsubsection{Animal Care, Maintenance and Preparation}

Adult giant acorn barnacles, Balanus nubilus, of similar size were collected on SCUBA from pier pilings at the California Polytechnic State University's Center for Coastal Marine Science pier facility in Avila Beach, California, USA. Immediately post collection animals were scraped clear of epibiotic growth and morphometric measurements (mass, height, carino-rostral aperture length, aperture width, base length, base width, scutal length, scutal width) were recorded for each barnacle. Animals were held at this facility for a minimum of two weeks in a 200 I holding tank supplied with well-oxygenated, unfiltered seawater (temp: $11-13^{\circ} \mathrm{C}$; salinity: $33-34 \mathrm{ppt}$; ambient photoperiod) by way of a continuous flow-through system. Animals fed on plankton naturally present in the unfiltered, raw seawater. Animals used in these experiments ranged in size from 32-54 mm carino-rostral aperture length, 325-1173 g mass and $60-130 \mathrm{~mm}$ shell height. There was no barnacle mortality over the course of these experiments.

\subsection{Exposure Conditions and Experimental Design}

\subsubsection{Acute Experimental Protocol}

Barnacles were haphazardly transferred to individual (38 I), closed-system experimental tanks ( 3 tank replicates for each treatment, $n=3$ barnacles per tank; $\mathrm{N}=27$ ) stationed outside under ambient photoperiod. All experimental tanks were 
randomly arranged within a much-larger acrylic holding tank filled with constant, flow-through seawater pumped from an inflow pipe at a seawater depth of $10 \mathrm{~m}$, directly below the pier facility. This larger tank was designed to maintain the temperature of the experimental tanks at ambient ocean temperature conditions. Before experimentation, barnacles were held in the experimental tanks for $24 \mathrm{~h}$ in $8 \mathrm{I}$ of continuously aerated, unfiltered seawater (33-34ppt; mean: $12.65 \pm 0.46^{\circ} \mathrm{C}$, range: $\left.11.99-13.45^{\circ} \mathrm{C}\right)$.

Following $24 \mathrm{~h}$ acclimation, barnacles were exposed to normoxic immersion (control), anoxic immersion or air emersion for 6 h. Normoxic control animals were submerged in filtered sea water (FSW) that was continuously bubbled with atmospheric air. Anoxic immersion animals were submerged in FSW continuously bubbled with pure nitrogen gas $\left(\mathrm{pO}_{2}\right.$ levels in the FSW fell below $0.5 \mathrm{mg} / \mathrm{L}$ in $30 \mathrm{~min}$ ). Air emersion treatment tanks were emptied of water and animals were held exposed to the air. Data-loggers (HOBO Pendant ${ }^{\circledR}$ Temperature/Light Data Logger, Onset Computer Corp., Bourne, MA, USA) were placed into experimental tanks and temperatures were recorded every 5 min throughout the $6 \mathrm{~h}$ exposure period (normoxia: $14.39: \pm 0.10^{\circ} \mathrm{C}$; range: $11.54-$ $18.49^{\circ} \mathrm{C}$; anoxia: $13.00: \pm 0.04^{\circ} \mathrm{C}$; range: $11.25-15.06^{\circ} \mathrm{C}$; emersion: $18.65: \pm$ $0.23^{\circ} \mathrm{C}$; range: $13.16-26.13^{\circ} \mathrm{C}$ ). At the end of the 6 hours, barnacles were removed from their tanks and hemolymph and muscle (scutal adductor and tergal depressor) tissue samples were rapidly collected as described in each of the sections below. 


\subsubsection{Chronic Experimental Protocol}

Barnacles were haphazardly transferred to individual (160 I), indoor experimental tanks ( 4 tank replicates for each treatment, $n=3$ barnacles per tank; $\mathrm{N}=36$ ), which were part of a customizable tidal simulator system (Tide Simulator 1.0; skillfully built by our in-house equipment technicians Robert and Douglas Brewster). The tidal simulator system controlled for temperature, water level, water source and photoperiod (12h:12h light cycle) by way of an Arduino coded microcontroller. Before experimentation, barnacles were held in these experimental tanks for $24 \mathrm{~h}$ in $160 \mathrm{I}$ of continuously aerated, unfiltered seawater (33-34ppt; mean: $16.03 \pm 2.13^{\circ} \mathrm{C}$, range: $13.83-20.03^{\circ} \mathrm{C}$ ). Following $24 \mathrm{~h}$ acclimation, barnacles were exposed to cyclic normoxic immersion (control), anoxic immersion or aerial emersion for $6 \mathrm{~h}$, twice daily (6:00-12:00 and 18:0024:00) over a two-week period.

Treatment conditions (normoxia, anoxia, and emersion) were achieved in the same manner as in the acute exposure experiment $\left(\mathrm{pO}_{2}\right.$ levels in the anoxic treatment fell below $0.7 \mathrm{mg} / \mathrm{L}$ in $30 \mathrm{~min}$ ). When not experiencing their respective treatment conditions, barnacles were all exposed to continuous flow-through seawater. For 2 hours during each of these 6-hour between-treatment flowthrough periods, raw seawater was pumped through the tanks to provide a planktonic food source. Filtered seawater was used at all other times to minimize system biofouling. Data-loggers were placed into experimental tanks and temperatures were recorded every $5 \mathrm{~min}$ throughout the $6 \mathrm{~h}$ exposure period (Normoxia: mean: $16.23 \pm 0.02^{\circ} \mathrm{C}$; range: $13.81-18.87^{\circ} \mathrm{C}$; Anoxia: mean: 15.75 
$\pm 0.02^{\circ} \mathrm{C}$; range: $13.79-18.84^{\circ} \mathrm{C}$; Emersion: mean: $15.72 \pm 0.02^{\circ} \mathrm{C}$; range:

$\left.12.85-19.37^{\circ} \mathrm{C}\right)$. Hemolymph and muscle tissue samples were rapidly collected (as described below) at the end of the final 6hr treatment period.

\subsection{Hemolymph Gas and Electrolyte Measurements}

A single hemolymph sample $(\sim 400 \mu \mathrm{L})$ was collected from the rostral sinus (RS) by piercing through the anterior surface of the opercular membrane using a $1 \mathrm{ml}$ syringe fitted with a 25 -gauge $1 \frac{1}{2}$-inch needle. Samples were immediately analyzed for $\mathrm{pO}_{2}, \mathrm{pCO}_{2}, \mathrm{pH}, \mathrm{Na}^{+}, \mathrm{Cl}^{-}, \mathrm{K}^{+}$, and $\mathrm{Ca}^{+}$via an $\mathrm{ABL} 90 \mathrm{Flex}$ Blood Gas Analyzer (Radiometer Medical ApS, Brønshøj, Denmark) All samples were run in duplicate. Final $\mathrm{pH}$ and $\mathrm{pO}_{2}$ values were temperature corrected owing to the difference in the temperature of the hemolymph $\left(\sim 14^{\circ} \mathrm{C}\right)$ and the blood gas analyzer measurement conditions $\left(37^{\circ} \mathrm{C}\right)$. Based on our own pilot trials on the ABL90 FLEX, we generated the following equation to correct for $\mathrm{pO}_{2}$ :

$$
\text { Corrected } \mathrm{pO}_{2}=\frac{\left(\text { Measured } \mathrm{pO}_{2}-11.443\right)}{1.3421}
$$

The $\mathrm{pH}$ temperature correction equation (Eq. 2) was based on the work of Ashwood et al. (1983):

$$
\text { Corrected } p H=\text { Measured } p H-\frac{0.0147}{14-37}
$$


In our pilot studies we did not detect any effects of temperature on $\mathrm{pCO}_{2}$ nor $\mathrm{pH}$ values on this device. We therefore did not perform a temperature correction on our $\mathrm{pCO}_{2}$ or $\mathrm{pH}$ values.

\subsection{Enzyme and D-lactate Assays}

SA and TD muscles were rapidly excised, flash-frozen in liquid nitrogen, and stored at $-80^{\circ} \mathrm{C}$. We subsequently quantified enzyme activity of citrate synthase (CS) and lactate dehydrogenase (LDH) in the SA and TD muscles via standard spectrophotometric assays (based on: Walsh \& Henry, 1990; Boyle et al., 2003; Johnson et al., 2004). Tissue samples ( 100mg) were homogenized via a motorized homogenizer (Fisher Scientific ${ }^{T M}$, Pittsburgh, PA, USA) in a 5fold excess (100 mg tissue in $500 \mu \mathrm{l})$ of protein extraction buffer $(50 \mathrm{mM}$ Tris, $1 \mathrm{mM}$ EDTA, $2 \mathrm{mM} \mathrm{MgCl}_{2}, 2 \mathrm{mM}$ DTT, $\mathrm{pH}$ 7.6), centrifuged for 20 minutes at $16,000(X g)$, and supernatants were stored at $-80^{\circ} \mathrm{C}$ until further analysis. To assess LDH activity, $10 \mu \mathrm{l}$ of 1:10 diluted sample supernatant (in Tris-HCl buffer; $\mathrm{pH}$ 7.6) was added to $1940 \mu \mathrm{L}$ of $0.12 \mathrm{mM} \mathrm{NADH}$ (in Tris- $\mathrm{HCl}, \mathrm{pH}$ 7.6). The reaction was begun with the addition of $50 \mu \mathrm{l}$ of $80 \mathrm{mM}$ pyruvate (to give a final concentration of $2 \mathrm{mM}$ pyruvate; final volume $2 \mathrm{~mL}$ ). $\mathrm{LDH}$ activity ( $\mu \mathrm{mol} \mathrm{min}^{-1} \mathrm{~g}$ tissue $^{-1}$ ) was determined from the change in absorbance at $340 \mathrm{~nm}$ (NanoPhotometer P300 Implen, Inc, Westlake Village, CA, USA) over 5 min. To assess CS activity, $50 \mu \mathrm{l}$ of undiluted sample supernatant was combined with $1900 \mu \mathrm{l}$ of Tris-HCl buffer (0.1mM DTNB, 0.1mM Acetyl CoA; $\mathrm{pH}$ 8.1). Once a stable baseline was achieved ( $<5 \mathrm{~min}$ ), the reaction was begun with the addition 
of $50 \mu$ of $20 \mathrm{mM}$ oxaloacetate (final concentration $0.5 \mathrm{mM}$ oxaloacetate; final volume $2 \mathrm{~mL})$. CS activity $\left(\mu \mathrm{mol} \mathrm{min}^{-1} \mathrm{~g}\right.$ tissue ${ }^{-1}$ ) was determined from the change in absorbance at $412 \mathrm{~nm}$ over $5 \mathrm{~min}$. Total protein measurements were determined using a Pierce ${ }^{\mathrm{TM}}$ BCA Protein Assay Kit (Thermo Scientific, Rockford, IL, USA) and a Multimode Plate Reader (Perkin Elmer, Waltham, MA, USA) to allow all enzyme activity measurements to be reported in the final units of $\mu \mathrm{mol}$ $\min ^{-1} \mathrm{mg}$ protein ${ }^{-1}$.

D-lactate levels were quantified from the SA and TD muscle using a Dlactate Colorimetric Assay Kit (Sigma-Aldrich, St. Louis, MO, USA). Tissue samples $(\sim 30 \mathrm{mg})$ were homogenized in a 5 -fold excess of D-lactate assay buffer, centrifuged for 10 minutes at $10,000 \times \mathrm{g}$, and supernatants were stored at $-80^{\circ} \mathrm{C}$ until further analysis. To quantify D-lactate, $50 \mu \mathrm{l}$ of 1:10 diluted sample supernatant (in D-lactate assay buffer) was added to $46 \mu \mathrm{l}$ of D-lactate assay buffer, $2 \mu$ of D-lactate enzyme $\mathrm{mx}$, and $2 \mu \mathrm{l}$ of D-lactate substrate mix and allowed to incubate for 30 minutes. Endpoint absorbance values were measured at $450 \mathrm{~nm}$ for each sample on Multimode Plate Reader (Perkin Elmer, Waltham, MA, USA). D-lactate levels (mM) were then determined by comparison to a standard curve.

\subsection{Histology}

Only muscle samples from the chronic experiment were processed for histological analysis. The SA and TD muscle tissues from three barnacles per treatment group were rapidly excised and cleared of connective tissue. A subset 
of 5 fibers per muscle group was embedded in Tissue-Tek Optimal Cutting Temperature (OCT) compound within a disposable plastic Cryomold®. Given their large size, individual fibers could easily be identified and teased apart by eye. Cryomolds were frozen in liquid nitrogen-cooled isopentane for $30 \mathrm{~s}$, wrapped in parafilm, and stored at $-80^{\circ} \mathrm{C}$ until further histological processing. Samples were moved to a $-20^{\circ} \mathrm{C}$ freezer $24 \mathrm{~h}$ prior to cryosectioning. After this time samples were removed from the cryomold, mounted on to a round metallic chuck with OCT, and acclimated for 20 minutes in a microtome cryostat (Bright Installation Company, London, England). Cross-sections (12 $\mu \mathrm{m}$ thick for WGA and DAPI; $30 \mu \mathrm{m}$ thick for SDH) were collected at equal distances across the entire length of each muscle fiber (totaling $~ 10-15$ sections per fiber). Frozen sections were collected on room temp slides (Superfrost plus) and air-dried for at least 2 minutes prior to staining.

After air-drying, WGA and DAPI sections were fixed in $4 \%$ paraformaldehyde (in 0.1M PBS; $\mathrm{pH} 7.4$ ) for 5 min, permeabilized in $0.1 \%$ Triton $\mathrm{X} 100$ (in $0.1 \mathrm{M}$ PBS) for $5 \mathrm{~min}$, and washed three times ( 5 min each) with $0.1 \mathrm{M}$ PBS. Sections were then stained for $30 \mathrm{~min}$ in $2.86 \mu \mathrm{M}$ DAPI (to visualize nuclei), and $43 \mathrm{nM}$ Alexa Fluor 488 conjugated wheat germ agglutin (WGA; to visualize the sarcolemma), before being washed three times (10 min each) in 0.1M PBS. A subset of tissue samples was processed using the same protocol (above) for SDH staining. After air-drying for 15 minutes, SDH sections were incubated in $0.2 \mathrm{M}$ sodium succinate dibasic (anhydrous) solution (in $0.2 \mathrm{M} \mathrm{PBS} ; \mathrm{pH} 7.6$ ) for $1 \mathrm{~h}$, rinsed with $0.2 \mathrm{M}$ PBS, fixed in $10 \% \mathrm{NaCl}$ with $10 \%$ neutral buffered formalin 
(NBF), and rinsed again with 0.2M PBS. All slides were air dried for 10 minutes and sections covered with FluorSaveReagent ${ }^{\mathrm{TM}}$ prior to mounting the cover slip. Slides were dried overnight before viewing and imaging.

Stained cross-sections were examined with an Olympus BX60 Fluorescence Microscope and imaged with an Olympus XM10 camera (Olympus, Tokyo, Japan). From these images, fiber margins were traced using Adobe Photoshop, and resultant polygons were analyzed with Image $\mathrm{J}$ version $1.50 \mathrm{i}$ to calculate fiber cross-sectional area (CSA) and feret's diameter. Feret's diameter is the perpendicular distance between two imaginary parallel tangential lines determined from the angle of the length and width of the object. Due to the tremendous nuclear densities in these large fibers, nuclear counts were determined inside two $300 \mu \mathrm{m}$-diameter circular subsampling regions. One sampling circle was placed directly in the center of the fiber section, and another along the fiber's edge. For each tissue cross-section, the final nuclear count was calculated as the average from each of the two sampling regions. The number of nuclei per millimeter of fiber $(\mathrm{X})$ was then calculated as described by Schmalbruch and Hellhammer (1977), using the equation:

$$
X=N L /(d+l)
$$

where $\mathrm{N}$ is the average number of myonuclei from a fiber's two sampling regions, $L$ is the desired length of segment (i.e., $1 \mathrm{~mm}$ ), $d$ is the thickness of the section, and $I$ is the mean length of a muscle nucleus. $L$ was set at $1,000 \mu \mathrm{m}$, $d$ was set to 
$12 \mu \mathrm{m}$, and I was estimated to be $15 \mu \mathrm{m}$ (Hardy et al., 2009). From this $X$ value, we calculated the myonuclear domain [i.e., the volume of cytoplasm per myonucleus (Y)] using the equation from Rosser et al. (2002):

$$
Y=C L / X
$$

where $C$ is the cross-sectional area of the fiber sampling region, $L$ is the length of the fiber segment, and $\mathrm{X}$ is the number of myonuclei per millimeter of fiber determined from Eq. 3.

\subsection{Statistical Analyses}

All statistical analyses were conducted using JMP Pro software (v. 11.1). Data were tested for normality using the Shapiro-Wilk test, and for homogeneity of variance using the Levene test. Data that failed to conform to these assumptions were log transformed before proceeding with parametric statistics. One-way ANOVA models were used to determine if there were any significant treatment effects (normoxic immersion, anoxic immersion or aerial emersion) on $\mathrm{pO}_{2}, \mathrm{pCO}_{2}, \mathrm{pH}$, and electrolyte concentration $\left(\mathrm{Na}^{+}, \mathrm{Cl}^{-}, \mathrm{K}^{+}\right.$, and $\left.\mathrm{Ca}^{2+}\right)$, as well as D-lactate concentration. We used ANCOVA models (with scutal length as our covariate) to determine treatment effects on CS and LDH enzyme activity, as well as muscle histological parameters (fiber cross-sectional area and Feret's diameter) (Based on a multivariate analysis of all barnacle size morphometrics measured, sctual length $(\mathrm{SL})$ was the best correlate to muscle fiber diameter or 
CSA). In order to normalize to fiber size, we used an ANCOVA (with fiber crosssectional area as our covariate) to determine treatment effects on myonuclear domain. When significant main effects were detected in the ANOVA or ANCOVA models, post-hoc pairwise comparison tests were performed using a Tukey's HSD tests. Student's or paired t-tests were used to determine if there was any significant effect of tissue (SA versus TD) on the same parameters. All values are reported as mean \pm SEM. All results were considered to be significant at the $\alpha=0.05$ level. 


\section{RESULTS}

\subsection{Hemolymph Gas and Electrolytes}

Acute exposure (6h) to oxygen-limiting conditions had a significant effect on hemolymph $\mathrm{pO}_{2}$ (one-way ANOVA; $\mathrm{F}_{2,22}=5.8755, \mathrm{p}=0.0090$ ), whereby oxygen levels were significantly lower in barnacles subject to anoxic immersion (A), relative to both the normoxic immersion control $(\mathrm{N})$ and the air emersion $(\mathrm{E})$ treatment groups (Fig. 3A). A similar pattern was observed in barnacles that experienced chronic ( $2 \mathrm{wk}$ ) exposure to the same oxygen-limiting tidal conditions (delivered twice daily for $6 \mathrm{~h}$ each) (one-way ANOVA; $F_{2,24}=4.8376, p=0.0172$ ). Barnacles experiencing chronic, cyclic anoxic immersion had significantly lower hemolymph $\mathrm{pO}_{2}$ than barnacles under air emersion, though not normoxic immersion (Fig 3B).

Hemolymph $\mathrm{pCO}_{2}$ also changed significantly following both acute $\left(F_{2,23}=13.7089, p=0.001\right)$ and chronic $\left(F_{2,24}=20.8031, p<0.001\right)$ exposure to lowoxygen tidal conditions. In each case, $\mathrm{pCO}_{2}$ was significantly lower in the anoxic immersion barnacles, compared to the normoxic and air emersion barnacles (Fig. $3 \mathrm{C}, \mathrm{D})$. As expected, hemolymph $\mathrm{pH}$ followed the inverse trend of $\mathrm{pCO}_{2}$ under both acute $\left(F_{2,23}=4.493, p=0.0225\right)$ and chronic $\left(F_{2,24}=5.4233, p=0.0114\right)$ exposure, such that the barnacles in anoxia had a significantly higher $\mathrm{pH}$ than normoxic control barnacles (Fig. 3E,F). An additional regression analysis revealed a significant linear relationship between $\mathrm{pCO}_{2}$ and $\mathrm{pH}$ following both acute $\left(\mathrm{F}_{1,24}=13.2945, \mathrm{p}=0.0013, \mathrm{R}^{2}=0.356, \mathrm{pH}=7.897-0.025^{*} \mathrm{pCO}_{2}\right)$ and chronic 
$\left(F_{1,25}=13.7025, p=0.0011, R^{2}=0.354, p H=7.842-0.023^{*} \mathrm{pCO}_{2}\right)$ exposure, which we observed collectively across all oxygen treatment (Fig. 4).

Following acute exposure, the hemolymph concentration of $\mathrm{Na}^{+}, \mathrm{Cl}^{-}, \mathrm{K}^{+}$ and $\mathrm{Ca}^{2+}$ did not vary significantly among treatment groups (one way ANOVAs; $\mathrm{Na}^{+}, \mathrm{p}=0.3695 ; \mathrm{Cl}^{-}, \mathrm{p}=0.9326 ; \mathrm{K}^{+}, \mathrm{p}=0.8731 ; \mathrm{Ca}^{2+}, \mathrm{p}=0.9640$ ) (Table 1). After chronic exposure, however, there were significant treatment effects for all electrolytes measured $\left(\mathrm{Cl}: \mathrm{F}_{2,8}=8.903, p=0.0092 ; \mathrm{K}^{+}: \mathrm{F}_{2,23}=6.9649, \mathrm{p}=0.0043\right.$; $\left.\mathrm{Ca}^{2+}: \mathrm{F}_{2,24}=3.4621, \mathrm{p}=0.0477\right)$, except $\mathrm{Na}^{+}(\mathrm{p}=0.064)$ (Table 1). Hemolymph $\left[\mathrm{Cl}^{-}\right]$, $\left[\mathrm{K}^{+}\right]$and $\left[\mathrm{Ca}^{2+}\right]$ were all significantly higher in barnacles held under anoxic immersion conditions than in the normoxic control barnacles, though the concentration of these ions varied respectively in the air emersion barnacles. Barnacles held in the air had $\left[\mathrm{Cl}^{-}\right]$that were no different than the control animals, whereas their $\left[\mathrm{K}^{+}\right]$levels were comparable to the anoxic immersion barnacles. The $\left[\mathrm{Ca}^{2+}\right]$ in the emersed barnacles was intermediate to both the normoxic and anoxic groups, and was not significantly different than either one.

\subsection{Enzyme Activity and D-lactate}

We found no significant treatment effect on citrate synthase (CS) activity or lactate dehydrogenase (LDH) activity in either SA or TD tissue, following acute or chronic exposure (one-way ANOVAs, $p \geq 0.103$ ) (Fig. 5). Further, we found no evidence that barnacle size influenced CS or LDH activity, as evidenced by a lack of correlation between these parameters and metrics of barnacle size (e.g., body mass, aperture width, scutal length, etc.) (Data not shown). Despite this 
finding, we ran additional ANCOVA analyses, with scutal length as the body size covariate, to remove any potential confounding influence of size on enzyme activity levels, and still did uncover any significant treatment effects $(p \geq 0.1153)$. There were however, strong tissue-specific differences in CS and LDH activity (Fig. 5). Baseline CS activity in normoxic barnacles was significantly higher in SA muscle after acute and chronic exposure (Student's t-test; acute: $F_{1,16}=5.4835$, $p=0.0325$; chronic: $F_{1,22}=38.8773, p<0.0001$ ), whereas baseline LDH activity was significantly higher in the TD muscle after acute and chronic exposure (Student's t-test; acute: $F_{1,16}=8.8257, p=0.0090$; chronic: $F_{1,22}=11.9113, p=0.0023$ ).

While CS and LDH enzyme activity were insensitive to the treatment conditions, the concentration of D-lactate was significantly affected by oxygen treatment in both the SA and TD muscles following acute exposure (one-way ANOVA; $S A: F_{2,24}=8.2988, p=0.0018$; TD: $\left.F_{2,24}=6.3627, p=0.0061\right)$. After 6h, $D-$ lactate levels were significantly higher in both SA and TD muscles from air emersed barnacles compared to normoxic barnacles, whereas, surprisingly, Dlactate levels were not significantly elevated above the control animals in the anoxic group (Fig. 6A). There was no significant difference in the [D-lactate] between the SA and TD muscles from normoxic control barnacles $(p=0.3994)$ in the acute experiment. Following chronic exposure to oxygen-limiting tidal conditions, however, there were no significant treatment effects on [D-lactate] (SA: $p=0.9501 ; T D=0.7380$ ), though baseline $D$-lactate levels (normoxic control only) were significantly higher in the SA muscle compared to TD muscle $\left(F_{1,22}=6.1166, p=0.0216\right)$ (Fig. 6B). 


\subsection{Histology}

Our histological analyses indicate that adult $B$. nubilus maintained in normoxic, subtidal conditions have an average muscle fiber diameter of $2005 \pm$ $95 \mu \mathrm{m}(\sim 2 \mathrm{~mm})$ in the SA muscle, and $2512 \pm 105 \mu \mathrm{m}(\sim 2.5 \mathrm{~mm})$ in the TD muscle (Fig. 7A). The TD muscles are significantly larger than the SA muscles, both in terms of their Feret's diameter and CSA (Fig. 7A, B), as determined by a paired t-test (diameter: $\left.\mathrm{t}_{(2)}=7.200, p=0.0187 ; \mathrm{CSA}: \mathrm{t}_{(2)}=6.768, \mathrm{p}=0.0211\right)$. Both SA and TD muscle fibers appear to be heavily subdivided, presumably by what originated as deep clefts/invaginations of the fibers' outer sarcolemma, and which can be seen in images of the SDH (Fig. 8A-D) and wheat germ-agglutinin stained fiber cross-sections (Fig. 9C,D). Succinic dehydrogenase staining enabled us to visualize the relative density and distribution of mitochondria in these fibers. From these images we can surmise two things. First, mitochondrial density is extremely low in both the TD (Fig. 8A,B) and SA (Fig. 8C,D) muscle fibers. This point is emphasized by the relatively intense SDH staining that can be seen in images of rat plantaris muscle (Fig. 8E,F) that were sectioned and stained directly alongside of the barnacle fibers so direct comparisons of mitochondrial density could be made to these fibers of known mitochondrial volume density (4\%; Bergeron et al., 2001). Second, mitochondria appear to predominantly align themselves with the subdivision/sarcolemmal edges (Fig. $8 A-D)$, and are not found in great enough density in the middle of the fiber/subdivision to be visualized by light microscopy. (Further TEM analysis of mitochondrial fractional volume and distribution will be pursued in the future). We 
have also determined that the myonuclei in both the SA and TD muscles are distributed across the entirety of the fiber, and not just beneath the sarcolemma, as is typical of most skeletal muscle cells. Upon thorough examination, it also appears that, like the mitochondria, the nuclei are closely aligned with the sarcolemmal and subdivision margins (Fig. 9). Further, the myonuclear domain size - or volume of cytoplasm 'serviced' by a single nucleus - was not significantly different between the two muscle types in our normoxic animals (one-way ANOVA; $p=0.3289$ ) (Fig. 7C).

After characterizing the structural properties of the SA and TD muscles, we investigated whether these properties exhibited plasticity in response to chronic exposure to oxygen-limiting tidal conditions. Our ANCOVA models (with sctual length as covariate) did not reveal any significant effect of oxygen treatment (tidal condition) on Feret's diameter or CSA in the SA (diameter: $p=0.1574$; CSA: $p=0.0921$ ) or TD muscle fibers (diameter: $p=0.9000$; CSA: $p=0.8259)$. There were, however, significant differences in the myonuclear domain size between treatments in the SA muscle (ANCOVA with fiber CSA as the covariate; $\left.F_{2,33}=5.3519, p=0.0097\right)$, though not TD muscle $(p=0.5710)$. The myonuclear domain was significantly larger in SA muscle from the normoxic control barnacles compared to both the anoxic immersion and air emersion barnacles (Fig. 7C). 


\section{DISCUSSION}

The giant acorn barnacle Balanus nubilus faces the unique metabolic challenge of preserving muscle function in fibers of extreme size (approaching $4 \mathrm{~mm}$ in diameter), where oxygen diffusion into and across the cell is likely to be limited. This feat is increasingly difficult given that $B$. nubilus also lacks a hemolymph oxygen binding pigment, and predictably encounters air emersion and hence potential difficulties with gas exchange - across the tidal cycle. For this reason, $B$. nubilus represents an ideal model for investigating the 'rules' for how oxygen availability influences muscle design. Here, we provide a baseline characterization of the giant scutal adductor (SA) and tergal depressor (TD) muscles in B. nubilus and present evidence for effects of oxygen limitation on their structural and metabolic properties.

\subsection{Muscle Characterization}

The SA and TD muscle of $B$. nubilus are indeed giant, with the TD muscles exceeding the SA muscles in both average diameter and CSA (Fig. 7). In the present study, the largest individual TD muscle fiber we measured had a diameter of $3.72 \mathrm{~mm}$, whereas the largest individual SA muscle was $2.81 \mathrm{~mm}$. As in other crustaceans (Boyle et al., 2003; Hardy et al., 2010), fiber size relates directly to growth of the animal, which was indicated by a strong correlation between metrics of body size (e.g., scutal length) and fiber diameter (SA: $p=$ 0.0050; $R^{2}=0.70$; TD: $p=0.0091, R^{2}=0.65$ ) or CSA (SA: $p=0.0074 ; R^{2}=0.67 ; T D$ : $p=0.0136, R^{2}=0.61$ ) in both tissues. At these sizes, $B$. nubilus fibers substantially 
exceed those of other crustaceans or fishes possessing giant muscle cells [e.g., blue crab, Callinectes sapidus, $620 \mu \mathrm{m}$; American lobster, Homarus americanus, $670 \mu \mathrm{m}$; stone crab, Menippe mercenaria, $763 \mu \mathrm{m}$; black sea bass, Centropristis striata, $208 \mu \mathrm{m}$ (Jimenez et al., 2010; Jimenez and Kinsey, 2012)]. Based on our images of WGA-stained fibers (Fig. 9C,D), we have evidence for distinct intracellular subdivisions within both the SA and TD muscle cells. These subdivisions appear to be invaginations of the outer sarcolemma, and are likely associated with the deep clefts characteristic of barnacle (Hoyle et al., 1973) and other crustacean fibers ( Peachey, 1967; Selverston, 1967; Hardy et al., 2009). Previous work estimates that the cleft space represents $8 \%$ or more of the total volume of individual fibers in B. nubilus, which have much coarser divisions than vertebrate fibers (Hoyle et al., 1973).

Mitochondrial density also appears to be extremely low in both SA and TD fibers, as Figure 8A-D reveals, and this becomes overwhelmingly apparent when the SDH-stained barnacle fibers are directly compared to rat (Rattus norvegicus) plantaris muscle fibers that were sectioned and stained in parallel (Fig. 8E,F). Mitochondrial fractional volume in rat plantaris muscle has been measured at 4.0-6.0\% (Bergeron et al., 2001), whereas blue crab levator swimming muscle are only $0.4-0.8 \%$ (Hardy et al., 2009), both of which appear to have substantially more intense SDH staining than we observed in B. nubilus. A TEM analysis of mitochondrial fractional volume and distribution in $B$. nubilus muscles will be pursued in the future. Though low in density, the mitochondria do appear to be situated predominantly alongside the branching invaginations emanating from the 
cell membrane (Fig. 8). From a functional standpoint this arrangement would be desirable, as it keeps mitochondria closest to the oxygen-containing hemolymph that directly perfuses the fibers, and likely the subdivisions themselves. In $C$. sapidus, for example, aerobic swimming muscles have fibers with individual subdivisions that are separately supplied with hemolymph, such that each subdivision functions as its own distinct metabolic unit separate from the larger cell, which contracts as a whole (Hardy et al., 2009). In B. nubilus, nuclei are distributed evenly throughout both TD and SA fibers (Fig. 8A,B).

All of these characteristics suggest that contraction in these fibers is powered aerobically, which is paradoxical given the fact that they remain contracted for long-periods of time while the scutal and tergal plates are closed, and oxygen levels are presumably low. This sustained opercular closure ability under potential hypoxia may be explained by the use of a 'catch' state in giant barnacle fibers, similar to that seen in molluscan muscles and to a lesser extent in vertebrate smooth muscle (Southwood, 1983; Galler et al., 2010).

Ultrastructural evidence that muscles from barnacles share these catch-like properties has been documented previously (Hoyle, 1987). If this is also true for B. nubilus, then their giant fibers would contract (per usual) following a single intracellular $\mathrm{Ca}^{2+}$ spike, then sustain a relatively high force contraction without additional $\mathrm{Ca}^{2+}$ or ATP input. During this catch state, fibers experience extremely slow relaxation rates, and contraction occurs at near basal $\mathrm{Ca}^{2+}$ levels, with very little active cross-bridge cycling (and hence very little ATP required) (Cohen, 1982; Galler et al., 2010). The giant muscle cells of $B$. nubilus may therefore 
represent a highly functional, primeval mash-up of both striated and smooth muscle, which may confer their impressive contractile abilities in the face of low oxygen availability.

\subsection{Hemolymph Gas and Electrolytes}

After establishing a baseline characterization of the SA and TD muscle structure, we looked for evidence that oxygen limitations associated with tidal emersion or anoxia would induce changes in the metabolism and structure of these uniquely massive muscle cells. In pursuing these data, we first needed to characterize the changes in the oxygen content in the hemolymph in response to air exposure - and by comparison anoxic immersion - and determine whether significant aerial respiration is occurring. Very little is known about the respiratory physiology of cirripede barnacles, including the relationship between gas exchange, oxygen consumption rates, activity level, and the environment. In barnacles, the mechanics of respiration and feeding are linked whereby the rhythmical movements of the cirri, maintained by a musculo-hydraulic system, help circulate water in and out of the mantle cavity and thereby supply oxygenated water to the gills (Anderson, 1994; Davenport and Irwin, 2003). There is also likely to be additional gas exchange that occurs directly across the cirri themselves as they move through the water (Newell and Northcroft, 1965; Anderson and Southward, 1987) We know that several barnacles show efficient $\mathrm{O}_{2}$ exchange when exposed to the air during low tide (Petersen et al., 1974; Innes, 1985; Vial et al., 1999; López et al., 2003; Gilman et al., 2013; Castro et 
al., 2015), a characteristic shared by terrestrial, air-breathing decapod crustaceans (Bridges and Brann, 1980; Grieshaber et al., 1994). The pacific gooseneck barnacle is a prime example of this intermittent terrestrialism, with substantially higher levels of oxygen consumption occurring during air exposure than during immersion (Petersen et al., 1974).

As predicted, $B$. nubilus exhibited a significant drop in hemolymph $\mathrm{pO}_{2}$ following acute exposure to anoxic submersion (Fig. 3A). This indicates that no new oxygen is being added to the hemolymph, as expected. In the absence of an oxygen source, hemolymph $\mathrm{pO}_{2}$ declines over the $6 \mathrm{~h}$ exposure period as existing oxygen stores are used to support even the most minimal levels of aerobic metabolism. In the acute emersed animals, however, the $\mathrm{pO}_{2}$ is not significantly different from the normoxic control group; there appears to be no substantial decrease in hemolymph $\mathrm{pO}_{2}$ during emersion (Fig $\left.3 \mathrm{~A}\right)$. These results tell us that B. nubilus is likely capable of and quite successful at gas exchange during air exposure. This result is corroborated by (unquantified) personal behavioral observations, whereby cirral beating was almost entirely absent in the anoxic animals, but barnacles in the air were often seen to open their operculum, and even frequently extend their cirri. Presumably, this behavior facilitates oxygenation of stored mantle cavity fluid from which the gills obtain oxygen. (Experiments aimed at quantifying these behaviors are currently underway.)

Similar results were obtained in the chronic experiment, in which we saw that hemolymph $\mathrm{pO}_{2}$ in the normoxic and air emersion animals were not significantly different, in fact it was noticeably higher in the emersion group. In the 
anoxic animals, however, $\mathrm{pO}_{2}$ was no longer significantly different from the control group (although it was still clearly lower on average), yet it was significantly lower than air emersed animals (Fig. 3B). We interpret this to mean two things. First, barnacles that routinely experience low tide emersion are extremely well suited to take up oxygen in the air and may anticipate the arrival and duration of air exposure so that they maximize aerial respiration. And second, barnacles experiencing acute bouts of anoxia that are infrequent or unassociated with normal tidal cycles experience a significant drop in hemolymph $\mathrm{pO}_{2}$, but barnacles that experience predictable, chronic anoxia appear to acclimate to the low oxygen conditions and so facilitate a smaller reduction (or none at all) in $\mathrm{pO}_{2}$, which may be achieved by lowering whole-animal metabolic rates [It should be noted that there was a high degree of individual variation in blood gas $\mathrm{pO}_{2}$ concentrations between barnacles within treatments. We can likely attribute this to variation in behavior, as we know from previous work that respiration and activity in filter feeders are linked, but for barnacles the relationship is not so straightforward (Burke, 1979; Innes, 1985; Anderson, 1994; Davenport and Irwin, 2003).]

While the treatment effects on hemolymph $\mathrm{pO}_{2}$ primarily shed light on aerial gas exchange in $B$. nubilus, the treatment effects on hemolymph $\mathrm{pCO}_{2}$ lend further insight into the metabolic response of $B$. nubilus under these conditions. For both the acute and chronic experiments, $\mathrm{pCO}_{2}$ also decreases significantly under anoxic immersion, though not during emersion (Fig. 3C,D). This suggests a general reduction in aerobic metabolism under anoxia, which is likely a way of 
lowering $\mathrm{O}_{2}$ demand when supply is low. This result is not surprising given that entrance into a state of metabolic depression, as a form of energy conservation, is a very common response to hypoxia or hypercapnia in intertidal invertebrates (Grieshaber et al., 1994; Reipschläger and Pörtner, 1996; Guppy, 2004; Desai and Prakash, 2009). The fact that $\mathrm{pO}_{2}$ levels were preserved during chronic anoxic immersion more so than in the acute treatment group, is additional support that $B$. nubilus undergoes a metabolic depression during anoxia.

Following chronic exposure, though not acute exposure, we also observed differences in the hemolymph concentration of $\mathrm{Cl}^{-}, \mathrm{K}^{+}$and $\mathrm{Ca}^{2+}$. Compared to the normoxic animals, concentrations of all measured ions were highest in the hemolymph of animals exposed to chronic anoxia. This difference was significant for all ions except $\mathrm{Na}^{+}$(Table 1). Of these ions, only the concentration of $\mathrm{K}^{+}$was also significantly higher than the control in the air emersion barnacles. The fact that we are seeing these treatment effects over a chronic scale and not after acute exposure indicates that barnacles are acclimating to a cyclically oxygenlimiting environment by adjusting the levels of these electrolytes, which we suspect is a form of long-term acid-base regulation. We believe the increase in $\mathrm{Cl}^{-}, \mathrm{K}^{+}$and $\mathrm{Ca}^{2+}$ ions observed during anoxia serves to fill an osmotic gap created by the efflux of buffering proteins (e.g. $\left.\mathrm{HCO}_{3}{ }^{-}\right)$associated with the alkalinization of the hemolymph (Fig. 3E,F and 4), a strategy that has been observed in both vertebrates (Booth et al., 1982; Ultsch et al., 1981) and invertebrates (Taylor and Whiteley, 1989; Jensen, 1990; Henry and Wheatly, 1992; Henry et al. 2012) alike. In other crustaceans, hypercapnia and hypoxia 
induced metabolic acidosis - the opposite change to that of our experiments - is often counteracted by an increase in circulating bicarbonate buffers in the blood, usually sourced from the shell, and a consequent decrease in ion concentration (Taylor and Whiteley, 1989; Jensen, 1990; Henry and Wheatly, 1992;

Dissanayake et al., 2010).

A second explanation for changes in ion concentration during anoxia is that B. nubilus gill transport mechanisms (mainly $\mathrm{Na}^{+} / \mathrm{H}^{+}$and $\mathrm{Cl}^{-} / \mathrm{HCO}_{3}{ }^{-}$ cotransporters), are activated in response to the acid-base disturbance. This leads to increased transport of certain electrolytes in or out of the hemolymph. In decapod crustaceans acid-base and osmotic balance are, in large part, regulated by the transport of bicarbonate and chloride ions, as well as sodium and hydrogen ions, at the cell membrane (Burnett et al., 1985, Henry and Wheatly, 1992; Dissanayake et al., 2010). Lobsters and crayfish are thought to shift plasma chloride levels when they are in the air in order to regulate $\mathrm{HCO}_{3}$ levels (Taylor and Whiteley, 1989). Similarly, rainbow trout are thought to use $\mathrm{Cl}^{-}$and $\mathrm{K}^{+}$to support acid-base balance in response to environmental acidification (Booth et al., 1982). Barnacles may also be using a similar strategy for acid base regulation under anoxia by increasing $\mathrm{Cl}^{-}$transport into, and subsequently $\mathrm{HCO}_{3}{ }^{-}$ out of the extracellular fluid. For B. nubilus, this decrease in hemolymph $\mathrm{HCO}_{3}{ }^{-}$ would counteract the alkalinization of the blood resulting from depressed $\mathrm{pCO}_{2}$ during anoxia. The correspondent increase in hemolymph $\mathrm{Cl}^{-}$would be supported by ions drawn from either the environment or from the tissues themselves, as seen in crayfish during anoxia (Taylor and Whiteley, 1989). 
The reasons for the observed increases in $\mathrm{Ca}^{2+}$ and $\mathrm{K}^{+}$are less clear, and in general less is known about the role of these ions in acid-base balance. There are several reports of $\mathrm{Ca}^{2+}$ and $\mathrm{K}^{+}$plasma concentrations fluctuating significantly in trout, carp, and other crustaceans as a result of exposure to environmental acidification, though these changes appear to be species specific (McDonald et al., 1980; Ultsch et al., 1981; Booth et al., 1982; Jensen, 1990; Spicer et al., 2007). We know that $\mathrm{Ca}^{2+}$ plays a major role in muscle contraction and since $B$. nubilus may use 'catch' tension, giant fiber contraction during opercular closure may only require an initial, single large intracellular $\mathrm{Ca}^{2+}$ spike. Further, if these barnacle fibers share characteristics of vertebrate smooth muscle during catchlike tension, a portion of the intracellular $\mathrm{Ca}^{2+}$ may be supplied by the extracellular hemolymph source (not just the sarcoplasmic reticulum), a characteristic very uncommon in skeletal muscle. Interestingly, $B$. nubilus has been observed to use extracellular supplies of $\mathrm{Ca}^{2+}$ to facilitate contraction (Southwood, 1983). What this means is that, normoxic barnacles that have more frequent, but shorter duration bouts of muscle contraction, will continuously require new $\mathrm{Ca}^{2+}$ input and so use up hemolymph $\mathrm{Ca}^{2+}$ more quickly; whereas, barnacles exposed to anoxia are likely less active, and therefore have less frequent, but longer bouts of muscle contraction that require less $\mathrm{Ca}^{2+}$ often, which would explain the 'excess' hemolymph $\mathrm{Ca}^{2+}$ in anoxic barnacles.

While this doesn't fully explain the phenomenon we are witnessing in $B$. nubilus, evidence of these ion fluctuations does suggest a complex pattern of ion exchange in the face of environmental change (e.g. hypoxia). The increase of 
these electrolytes $\left(\mathrm{Cl}^{-}, \mathrm{K}^{+}\right.$and $\left.\mathrm{Ca}^{2+}\right)$ after cyclical oxygen limitation, and not after the acute limitation, is also suggestive of an acclimation response to prolonged acid-base challenges presented secondarily to hypocapnia in the hemolymph. Booth et al (1982) found that the onset of reestablishing osmotic equilibrium in the plasma of rainbow trout also occurs slowly, as the changes in electrolytes were not evident in the first day of exposure, but only after 24 hours. Further research will be needed to determine the exact mechanism of ion regulation occurring under these oxygen-limiting conditions.

\subsection{Enzyme Activity and D-lactate}

Adding to the structural differences observed between the TD and SA tissues, we also have evidence for variation in metabolic activity of the key enzymes, citrate synthase (CS) and lactate dehydrogenase (LDH), between these two muscles. In both chronic and acute experiments, baseline (normoxic) CS activity was significantly higher in the SA muscle compared to the TD muscle (Fig. 5A,B). Conversely, LDH activity was significantly higher in the TD muscle compared to the SA muscle (Fig. 5C,D). These data imply that the SA muscle has a greater capacity for aerobic metabolism, whereas the TD muscle has a greater capacity for anaerobic metabolism. These differences in enzyme activity between the two muscle groups may be explained by differences in their respective function as well as behavioral attributes of the barnacle. Contraction of the scutal adductor is imperative for sustained opercular closure, whereas the tergal depressor only secondarily aids in this closure. More specifically, the TD 
muscle facilitates rapid, whole body retraction in to the shell during predator evasion attempts - a muscle action typically characterized by fast twitch, anaerobic muscles (Anderson, 1993). Perhaps the SA muscle needs a higher oxidative metabolic capacity to fuel continuous, prolonged contraction during opercular closure, despite the paradoxical co-occurrence of low oxygen at these times. The TD muscle, on the other hand, may possess an increased anaerobic metabolic capacity to power rapid, high force contractions homologous to burstescape contractions in crabs, shrimp and lobsters.

Despite tissue-specific differences, we did not find any evidence that air emersion or anoxic immersion influenced enzyme activity in either tissue in the acute or chronic experiment (Fig. 5). These data in combination with the $\mathrm{pO}_{2}$ and [D-lactate] data suggest that 1) air emersion is not really that challenging for $B$. nubilus and 2) B. nubilus is entering into a state of metabolic depression during anoxia as a functional response to low environmental oxygen. The lack of any significant changes in the activity of CS and LDH enzymes during air emersion or anoxic immersion may also reflect the possibility that these muscles persistently function under a state of hypoxia for the majority of the animal's life, even in normal, oxygen-saturated environmental conditions. Davenport and Irwin, (2003) found that hemolymph oxygen levels in three species of intertidal balanomorph barnacles often fell well below surrounding seawater maintained at $100 \%$ air saturation, with much individual variation due to opercular closing and cirral beating patterns. 
Unlike CS and LDH activity, the concentration of D-lactate - the metabolic end product of anaerobic fermentation via the LDH pathway - was responsive to tidal treatment in B. nubilus, though only in the acute experiment (Fig. 6). Here we see that barnacles exposed to the air had significantly higher D-lactate concentrations in both the SA and TD tissues than barnacles under normoxic conditions, and quite interestingly, higher than the anoxic group, (Fig. 6). We hypothesize that this increase in D-lactate production during acute air emersion results from an increased reliance on anaerobic metabolism during this time when the animal is unsure about the timing of reimmersion and remains closed to conserve water. The fact that we are not seeing this treatment effect after chronic exposure leads us to believe that animals under predictable, long-term emersion are acclimating to the cyclic nature of air exposure. These barnacles have come to rely solely on aerial oxygen uptake, given the short-term, predictable period of time in which they are emersed, and therefore, can decrease their dependence on supplemental anaerobic metabolism.

The lack of change in D-lactate concentration in the anoxic immersion animals during chronic exposure experiments corroborates the notion that $B$. nubilus is entering into a metabolic depression during low oxygen conditions in the water. Reducing metabolic rates is a common response to oxidative stress in marine subtidal invertebrates (Burke, 1979; Desai and Prakash, 2009). Burke (1979) performed a study involving three morphologically similar intertidal crabs, and found that the more subtidal species of the three (Pachygrapsus crassipes) decreased their metabolic rate by $35 \%$ during air exposure compared to 
submersion. The other two species abandoned aerobic metabolism under the same conditions and instead drastically increased lactate production and hence reliance on anaerobic metabolism (Burke, 1979). It is not surprising that $B$. nubilus, another largely subtidal crustacean, would also be capable of considerably decreasing metabolic rate (as evidenced by the lack of change in CS activity, LDH activity and D-lactate, as well as a failure of hemolymph $\mathrm{pO}_{2}$ levels to drop in the chronic experiment) during the low oxygen conditions associated with anoxic immersion.

In general, hypoxia induced lactate formation is common in crustacean hemolymph and muscle tissue (Pritchard and Eddy, 1979; Bridges and Brand, 1980; Burnett and Stickle, 2001; Lopez et al., 2003) and we were surprised to see so little accumulation under anoxia (and to a lesser extent emersion). Lopez et al. (2003) witnessed an increase in muscle D-lactate after acute air emersion in the subtidal balanomorph barnacle, Austromegabalnus psittacus, under similar experimental conditions. Both $A$. psittacus and $B$. nubilus exhibit efficient aerial respiration, and we suspect that they similarly rely on supplemental anaerobic metabolism during air exposure, though apparently the latter is only utilized during acute exposure to low tide and not during chronic predictable bouts (Fig. $6)$.

Beyond use as an indicator for anaerobic metabolism, lactate is known to modulate oxygen carrying capacity in the hemolymph of some marine invertebrates (Burnett and Stickle, 2001; Ocampo et al., 2003; Weber et al., 2008). In the blue crab and some lobsters, increased hemolymph [lactate] 
strongly correlates with increased hemocyanin oxygen binding affinity during hypercapnic hypoxia (Hagerman et al., 1990; Burnett and Stickle, 2001). While $B$. nubilus lacks the protein hemocyanin, it is possible that these barnacles transport oxygen via an unknown protein and that increased lactate production has similar effects on this oxygen binding protein to those observed in other crustaceans.

We also found that baseline levels of D-lactate were significantly higher in the SA muscle than in the TD muscle in the chronic experiment, though this is not the case after the acute experiment (Fig. 6). The fact that we are seeing higher D-lactate levels in the SA muscle across all treatments after chronic exposure may be a temperature or seasonality-driven effect. Our acute exposure experiments occurred in the slightly cooler springtime, whereas the chronic exposure experiment occurred in the warmer months of fall. We may be witnessing a general increase in metabolism, which would include anaerobic metabolism, with increasing temperature. Respiration, oxygen consumption, and oxygen-affinity are all known to change with temperature in crustaceans (Barnes and Barnes, 1969; Taylor, 1981; Castro et al., 2001), and it is possible that these seasonal effects have a far greater influence on the production of metabolic end products than those of emersion itself. Future respirometry experimentation and will clarify the extent of temperature effects on oxygen consumption and metabolism in B. nubilus. 


\subsection{Structural Plasticity}

Though differences are not evident in cross-sectional area (CSA) and Feret's diameter across treatments in either tissue, we do have evidence for muscle plasticity in the form of changes in myonuclear domain $\left(\mu \mathrm{m}^{3} /\right.$ nuclei) in the SA muscle though not the TD (Fig. 7). Myonuclear domain size significantly decreased in the cells of barnacles exposed to anoxic immersion and aerial emersion compared to the normoxic control barnacles (Fig. 7C). This means one of two things is happening. Either the volume of cytoplasm per myonucleus is decreasing as fibers themselves get smaller in response to poorly oxygenated waters and/or air exposure, or additional nuclei are being added into the cell. The former option is unlikely given that we did not see any difference in fiber diameter or CSA between treatment groups (Fig 7A,B). Although we do predict that with a longer chronic exposure times (e.g. 1-2 months) we would have seen changes in fiber size of either or both muscles. Hoppeler et al. (1990) saw a significant reduction of skeletal muscle cross sectional area in the vastus lateralis muscle of mountaineers following 8 weeks of exposure to high altitude, which was paired with a decrease in the volume of muscle mitochondria (Hoppeler et al., 1990). An increase in the number of nuclei in $B$. nubilus muscle under low $\mathrm{O}_{2}$ (presumably from adjacent satellite cells) might be in line with a general restructuring of the organelles inside each individual subdivision. We know this occurs in response to increasing diffusion limitations during ontogenetic growth in the giant aerobic muscle fibers of the blue crab (Hardy et al., 2009). Given that the SA muscle is 
the more oxidative muscle we examined (Fig. 5), we are not surprised to see fiber-size related changes in SA muscle and not the TD muscle.

\subsection{Summary}

Individual muscle fibers of $B$. nubilus exceed those of any other known organism, with TD muscle fibers approaching $4 \mathrm{~mm}$ in diameter in our study. The smaller SA muscle, which contracts to close the operculum, is evidently the more oxidative of the two tissues based on higher baseline CS activity and lower baseline LDH activity. Conversely, the larger TD muscle, which contracts to rapidly depress the animal in to the mantle cavity, is the more glycolytic tissue, and presumably has a lower oxygen demand. Both tissues have distinct intracellular subdivisions, evenly distributed nuclei, and extremely low mitochondrial densities. Nuclei and mitochondria associate along these invaginations, and so are in close proximity to the oxygen-containing hemolymph that likely fills the cleft space.

We found that $B$. nubilus can successfully acquire oxygen from the air during emersion, but is supplementing energetic demand during this time with anaerobic metabolism after acute exposure. In response to anoxic immersion, $B$. nubilus appears to decrease aerobic metabolism, though we have no indication that they are increasing anaerobic metabolism under these same conditions as no changes in D-lactate were observed. These data, in addition to decreased hemolymph $\mathrm{pO}_{2}$ and $\mathrm{pCO}_{2}$, suggests that this species is likely capable of substantially depressing their overall metabolic rate during hypoxia. The $\mathrm{pH}$ 
increases associated with this decreasing $\mathrm{pCO}_{2}$ present acid-base challenges that we predict are either directly or indirectly creating a shift in buffering proteins, most importantly $\mathrm{HCO}_{3}{ }^{-}$. The ions $\mathrm{Cl}^{-}, \mathrm{K}^{+}$, and $\mathrm{Ca}^{2+}$ are quite possibly filling an osmotic gap left by bicarbonate efflux in attempt to maintain acid-base balance under the alkalosis associated with anoxic immersion.

We have some indication of muscle plasticity occurring under conditions of hemolymph hypoxia, whereby myonuclear domain decreases under both emersion and anoxic immersion in the more oxidative SA tissue. Thus, B. nubilus may be restructuring organelles within intracellular subdivisions as a response to oxygen stress. Collectively, our baseline cell characterization and experimental data indicate that the sustained contraction in these giant muscle cells is highly impressive given the potential diffusion constraints associated with their size, the fact that these barnacles lack of an oxygen-binding pigment and that they inhabit the oxygen-limited intertidal zone. The acute and chronic oxygen-limiting conditions designed in this experiment are apparently not that stressful for $B$. nubilus. Everything we know about cell size and metabolism indicates that the regime we designed should be stressful. This may come back to the unique morphology and physiology of the giant acorn barnacle and the mechanisms supporting this feat may be more complex than our conventional understanding of vertebrate muscle function. This is an organism that uses a novel 'catch' mechanism similar to molluscan adductor muscle in order to sustain skeletal muscle contraction and they likely have very low metabolic rates. Hence, even 
with giant muscle fibers, the model organism, Balanus nubilus, may be very well adapted to coping with stressful oxygen-limiting conditions. 


\section{TABLES}

Table 1. Concentration (mM) of $\mathrm{Na}^{+}, \mathrm{Cl}^{-}, \mathrm{K}^{+}$and $\mathrm{Ca}^{2+}$ in $B$. nubilus hemolymph following exposure to normoxic immersion, air emersion, and anoxic immersion.

\begin{tabular}{lccc}
\hline Acute & & Treatment & \\
\cline { 3 - 3 } Electrolytes $(\mathrm{mM})$ & Normoxic (Control) & Air Emersion & Anoxic Immersion \\
\hline $\mathrm{Na}^{+}$ & $493.78 \pm 5.28^{\mathrm{a}}$ & $506.39 \pm 7.10^{\mathrm{a}}$ & $501.11 \pm 6.46^{\mathrm{a}}$ \\
$\mathrm{Cl}^{-}$ & $450.44 \pm 9.33^{\mathrm{a}}$ & $450.94 \pm 7.62^{\mathrm{a}}$ & $446.67 \pm 10.41^{\mathrm{a}}$ \\
$\mathrm{K}^{+}$ & $9.93 \pm 0.20^{\mathrm{a}}$ & $9.99 \pm 0.16^{\mathrm{a}}$ & $10.06 \pm 0.15^{\mathrm{a}}$ \\
$\mathrm{Ca}^{2+}$ & $7.69 \pm 0.09^{\mathrm{a}}$ & $7.69 \pm 0.07^{\mathrm{a}}$ & $7.66 \pm 0.09^{\mathrm{a}}$
\end{tabular}

Chronic

\begin{tabular}{lccc} 
Electrolytes $(\mathrm{mM})$ & Normoxic (Control) & Air Emersion & Anoxic Immersion \\
\hline $\mathrm{Na}^{+}$ & $475.20 \pm 2.15^{\mathrm{a}}$ & $480.50 \pm 3.40^{\mathrm{a}}$ & $486.33 \pm 3.56^{\mathrm{a}}$ \\
$\mathrm{Cl}^{-}$ & $459.60 \pm 2.46^{\mathrm{a}}$ & $455.00 \pm 2.47^{\mathrm{a}}$ & $480.67 \pm 7.98^{\mathrm{b}}$ \\
$\mathrm{K}^{+}$ & $9.36 \pm 0.11^{\mathrm{a}}$ & $10.06 \pm 0.17^{\mathrm{b}}$ & $9.83 \pm 0.12^{\mathrm{b}}$ \\
$\mathrm{Ca}^{2+}$ & $7.43 \pm 0.26^{\mathrm{a}}$ & $8.14 \pm 0.30^{\mathrm{ab}}$ & $8.29 \pm 0.18^{\mathrm{b}}$
\end{tabular}

Note: Means with different letters are significantly different (post-hoc Tukey's HSD, $\alpha=0.05$ ).

Values are means \pm SEM, $n=9$ barnacles per treatment group (except chronic $\left[\mathrm{Na}^{+}\right]$and $\left[\mathrm{Cl}^{-}\right], n=3$ per treatment group). 


\section{FIGURES}

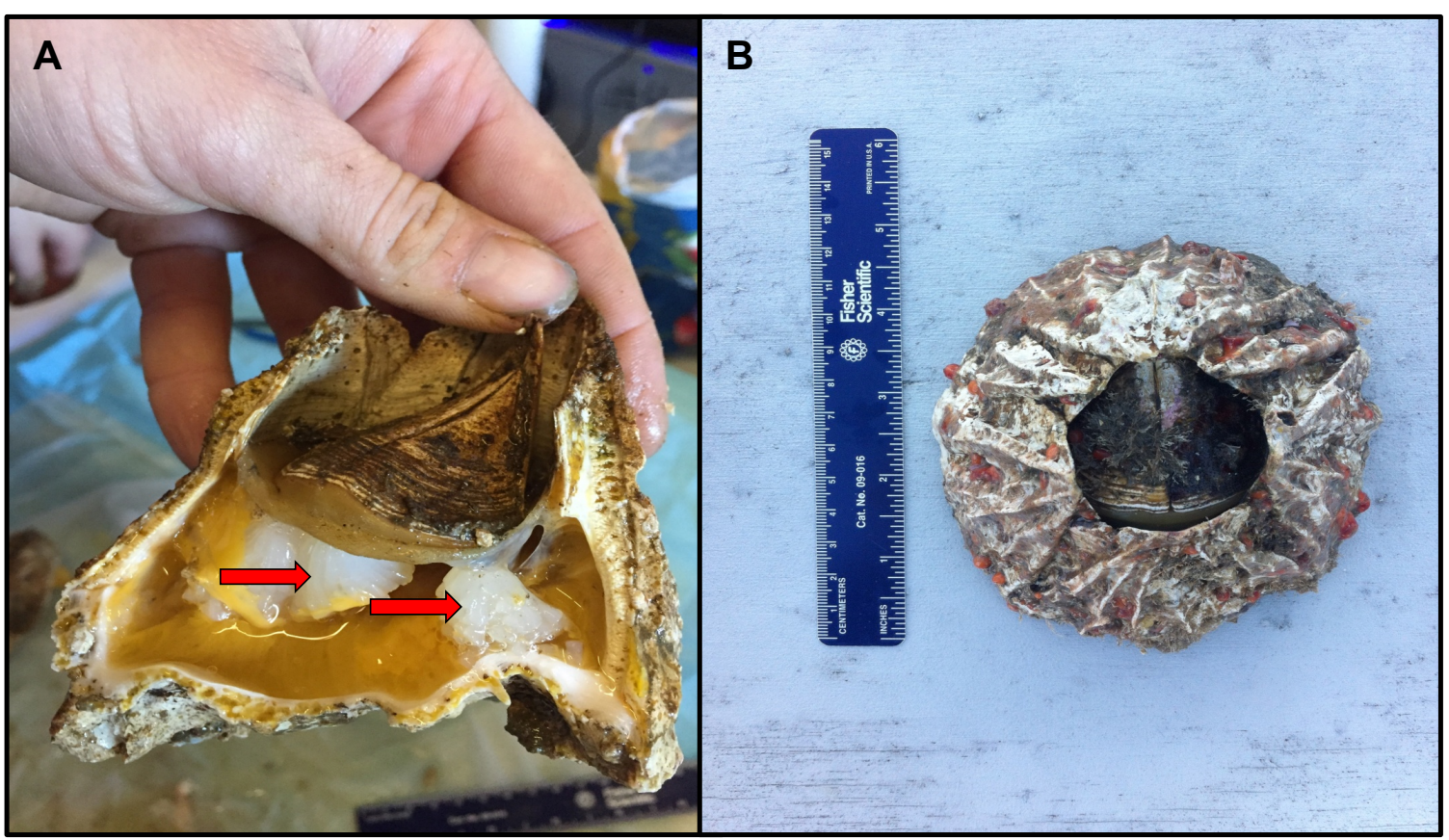

Fig. 1. Giant acorn barnacle, Balanus nubilus. (A) Lateral view of giant muscle fibers (red arrows), and (B) apical view to scale of Balanus nubilus. 


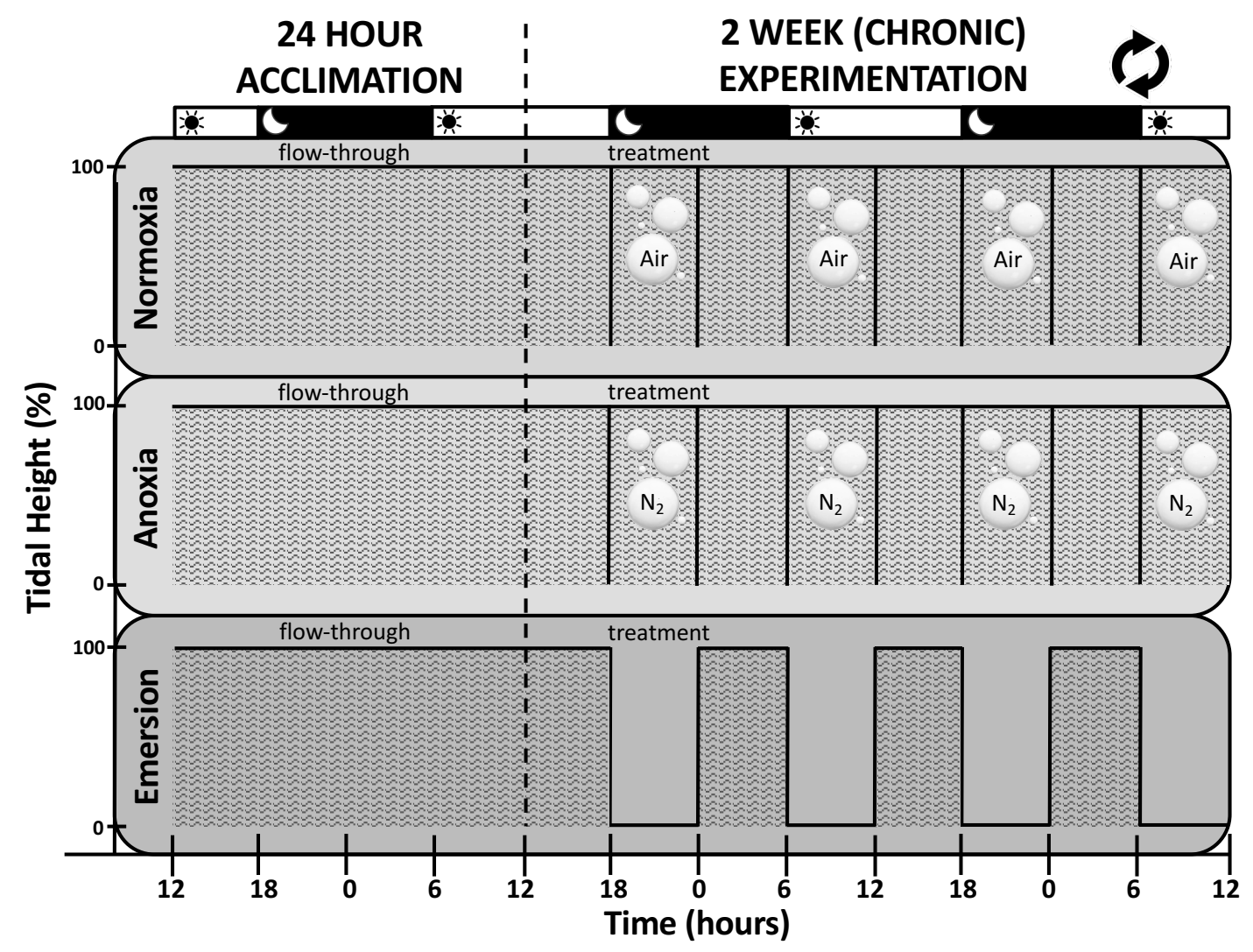

Fig. 2. Chronic exposure regime for $B$. nubilus. For two weeks barnacles were exposed twice daily for $6 \mathrm{~h}(6: 00-12: 00$ and 18:00-24:00) to one of the following oxygen-limiting tidal conditions: normoxic immersion (bubbled with atmospheric air; control), anoxic immersion (bubbled with pure nitrogen gas) and air emersion (exposed to the air). Barnacle tissues were sampled immediately at the end of final $6 \mathrm{~h}$ exposure period (12:00 on the $14^{\text {th }}$ day of experimentation). 

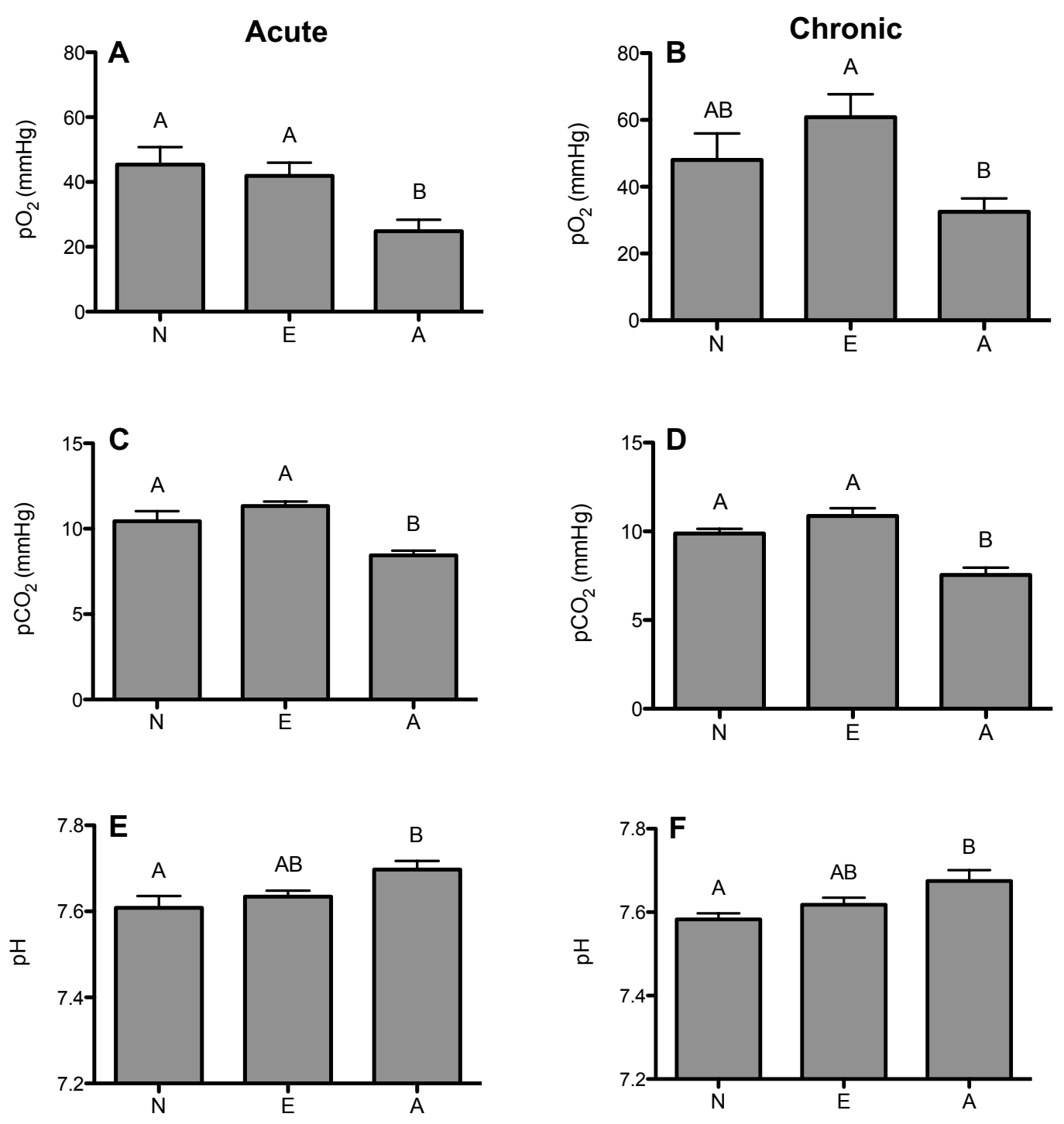

Fig. 3. Hemolymph $(\mathbf{A}, \mathbf{B}) \mathrm{pO}_{2}(\mathrm{mmHg}),(\mathbf{C}, \mathbf{D}) \mathrm{pCO}_{2}(\mathrm{mmHg})$ and $(\mathbf{E}, \mathbf{F}) \mathrm{pH}$ in $B$. nubilus following acute (left panel) and chronic (right panel) exposure to normoxic immersion $(N)$, air emersion $(E)$ and anoxic immersion $(A)$. Columns with different letters are significantly different (post-hoc Tukey's HSD test, $\alpha=0.05$ ). Values are means \pm SEM, $n=8-9$ barnacles per treatment group. 

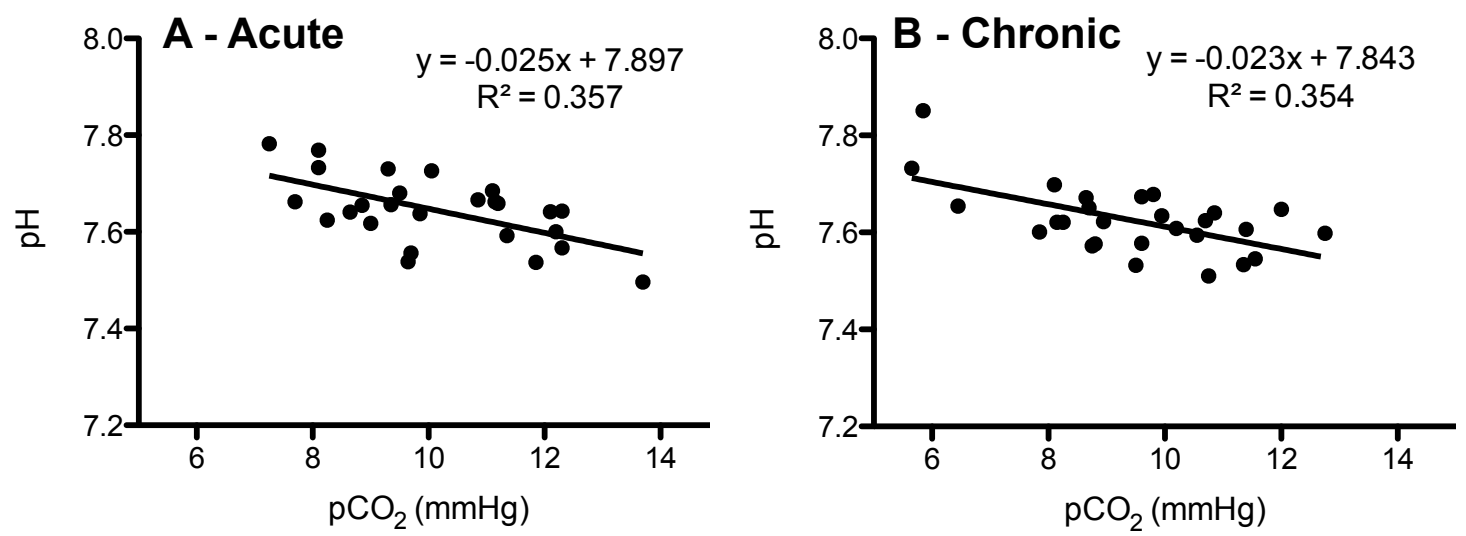

Fig. 4. Negative linear relationship between $\mathrm{pCO}_{2}$ and $\mathrm{pH}$ following both (A) acute and (B) chronic exposure to oxygen-limiting tidal conditions. Each data point represents the average hemolymph $\mathrm{pCO} 2$ and $\mathrm{pH}$ value from an individual barnacle taken at the end of the exposure period, and includes measurements from barnacles across all three treatments $(\mathrm{N}=27)$. 

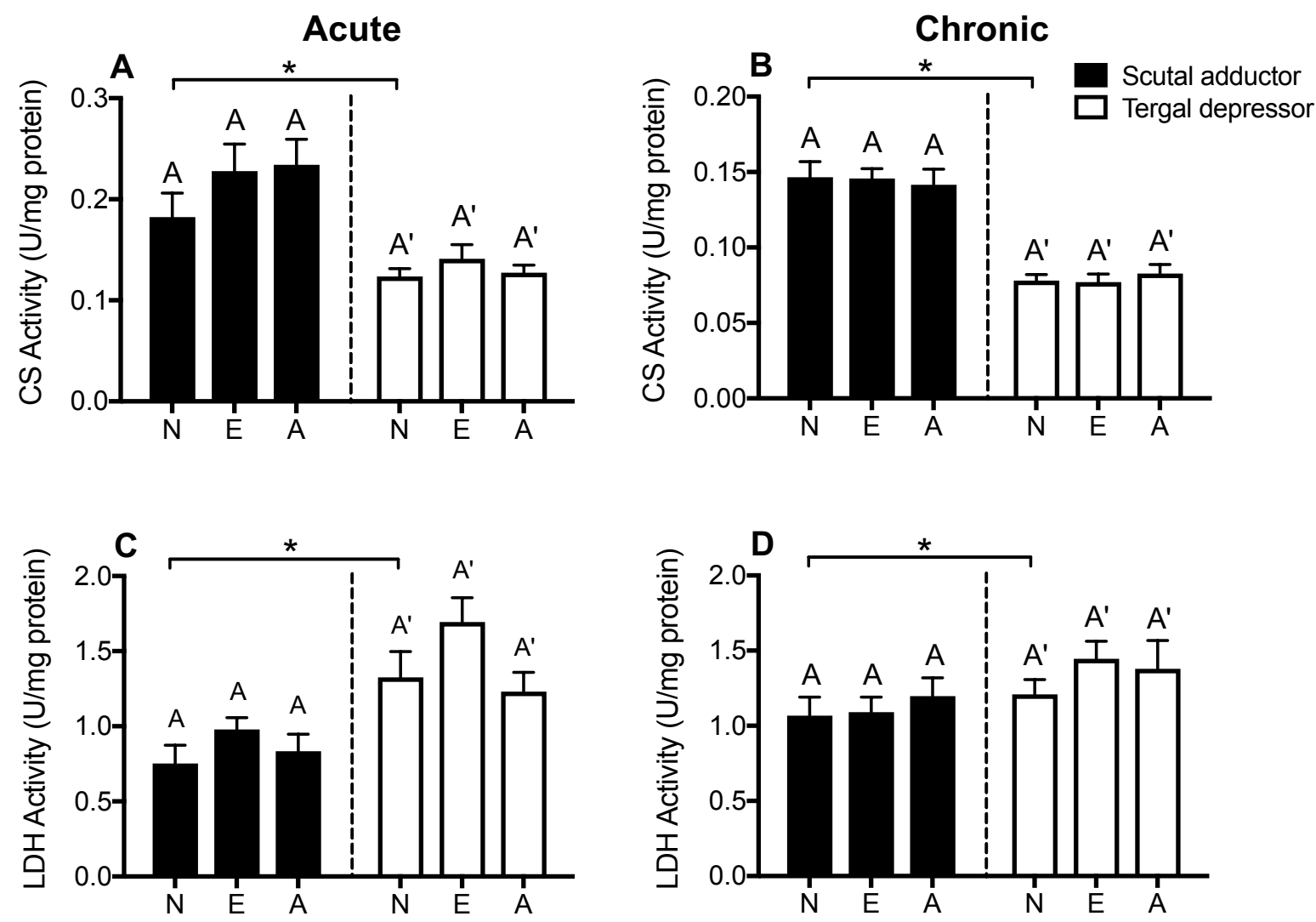

Fig. 5. Enzyme activity $\left(\mathrm{U} \mathrm{mg}^{-1}\right.$ protein) for (A,B) CS and (C,D) LDH in $B$. nubilus scutal adductor (black) and tergal depressor (white) muscles following acute (left panel) and chronic (right panel) exposure to normoxic immersion $(\mathrm{N})$, air emersion (E) and anoxic immersion (A). Within each tissue, columns with different letters are significantly different (post-hoc Tukey's HSD test, $\alpha=0.05$ ). Asterisks indicate means that are significantly different between muscle types in the $\mathrm{N}$ (control) treatment group (student's t-test, $\alpha=0.05$ ). Values are means \pm SEM, $n=9$ (acute) and $n=12$ (chronic) barnacles per treatment group. 
Acute

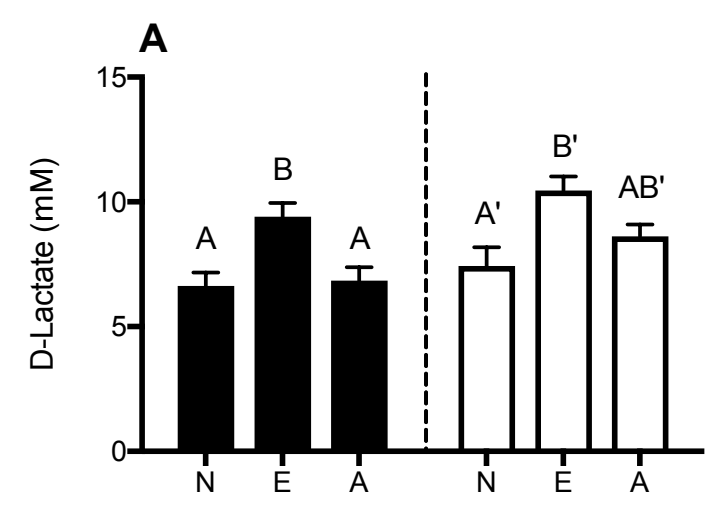

Chronic

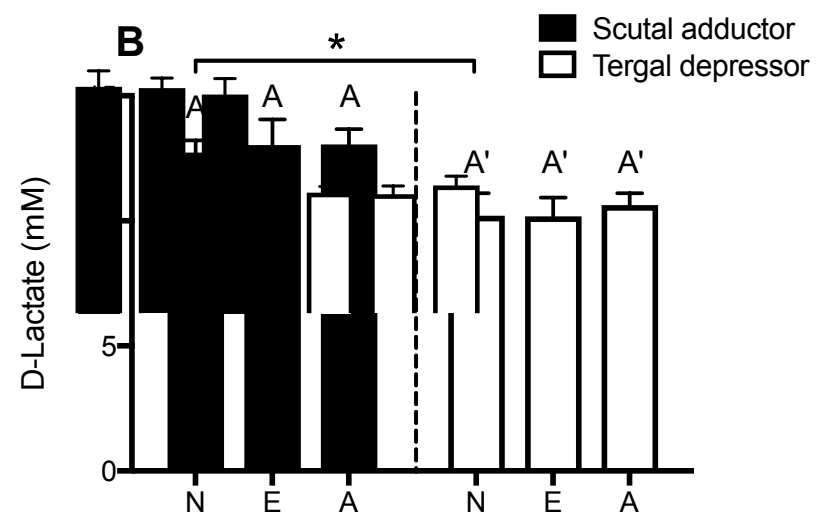

Fig. 6. D-lactate concentration (mM) in B. nubilus scutal adductor (black) and tergal depressor (white) muscles following $(\mathbf{A})$ acute and $(\mathbf{B})$ chronic exposure to normoxic immersion $(N)$, air emersion $(E)$ and anoxic immersion $(A)$. Within each tissue, columns with different letters are significantly different (post-hoc Tukey's HSD test, $\alpha=0.05)$. Asterisks indicate means that are significantly different between muscle types in the $\mathrm{N}$ (control) treatment group (student's t-test). Values are means \pm SEM, $n=9$ (acute) and 12 (chronic) barnacles per treatment group. 

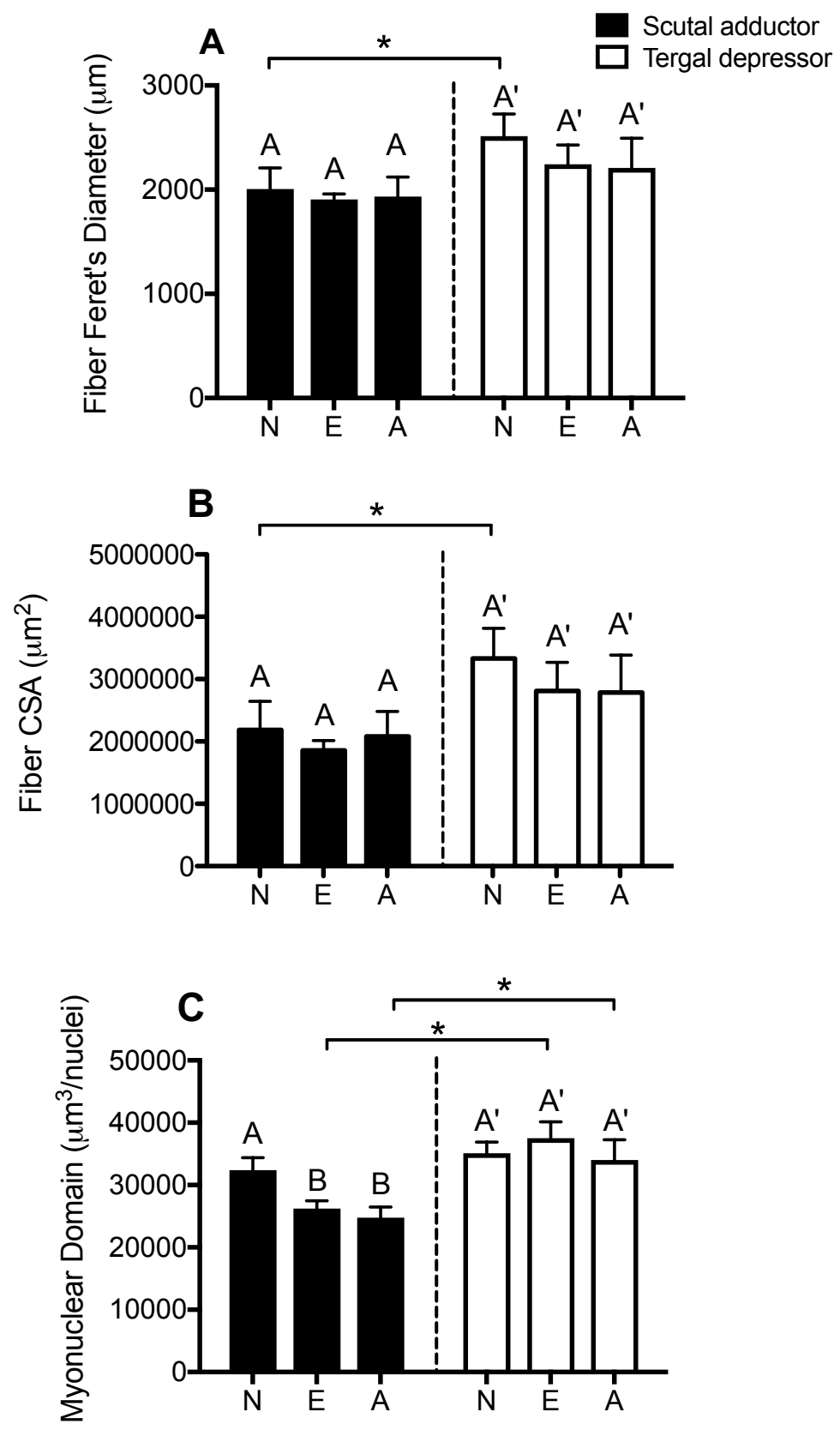

Fig. 7. The (A) Feret's diameter $(\mu \mathrm{m})$, (B) cross-sectional area $\left(\mu \mathrm{m}^{2}\right)$, and (C) myonuclear domain ( $\mu \mathrm{m}^{3} /$ nuclei) in $B$. nubilus scutal adductor (black) and tergal depressor (white) muscles following chronic (2wk) exposure to normoxic immersion (N), air emersion (E) and anoxic immersion (A). Within each tissue, columns with different letters are significantly different (post-hoc Tukey's HSD test, $\alpha=0.05$ ). Asterisks indicate means that are significantly different between muscle types from the same treatment group (paired t-test). Values are means \pm SEM, $n=15$ fibers (from $n=3$ barnacles) per treatment group for CSA and diameter, $n=10-15$ fibers (from $n=2-3$ barnacles) per treatment group for myonuclear domain. 


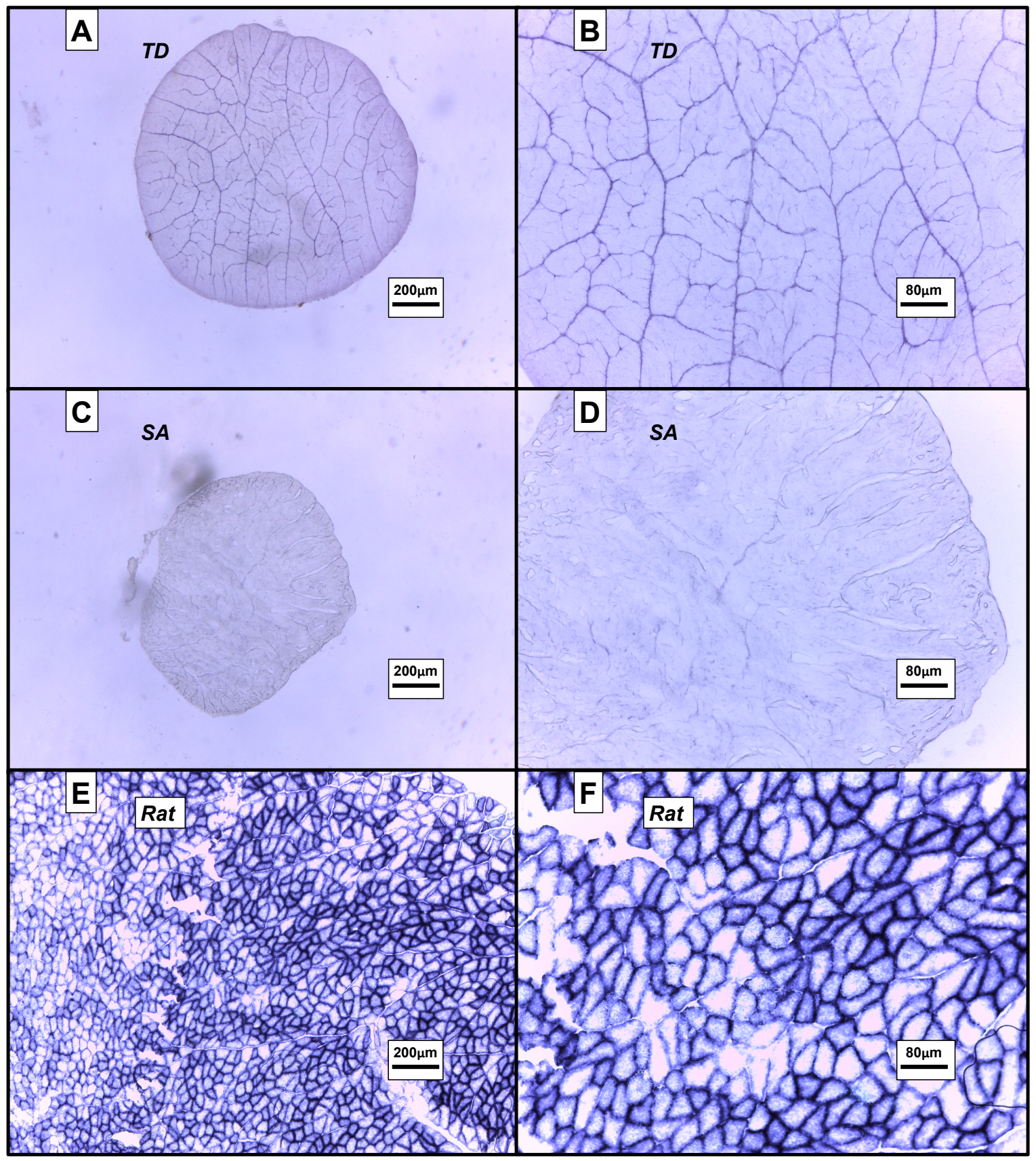

Fig. 8. Representative images of succinic dehydrogenase (SDH; mitochondrial stain) stained muscle fiber cross-sections $(30 \mu \mathrm{m})$ from $B$. nubilus $(\mathbf{A}, \mathbf{B})$ TD and (C,D) SA muscles. (E,F) Rat plantaris muscle that was sectioned $(30 \mu \mathrm{m})$, stained and imaged directly alongside the barnacle muscle to allow direct comparison of relative mitochondrial fractional volume (as indicated by staining intensity). Note the extremely low SDH staining intensity in both the TD and SA muscles compared to the rat muscles imaged under the same exposure conditions. Scale bar $=200 \mu \mathrm{m}(\mathbf{A}, \mathbf{C}, \mathbf{E})$ and $80 \mu \mathrm{m}(\mathbf{B}, \mathbf{D}, \mathbf{F})$. 


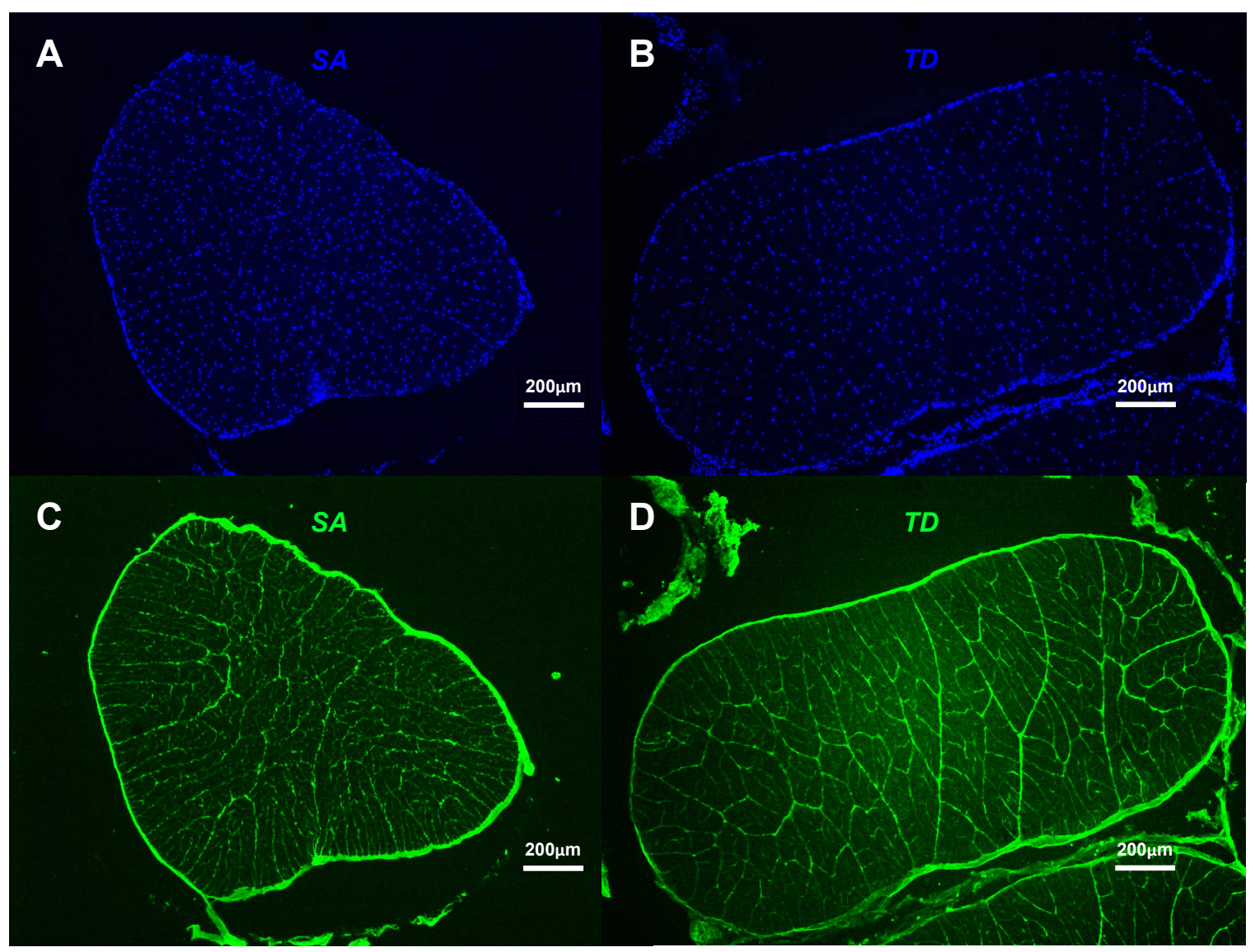

Fig. 9. Representative images of $B$. nubilus $(\mathbf{A}, \mathbf{C})$ scutal adductor and (B,D) tergal depressor muscle fiber cross-sections $(12 \mu \mathrm{m})$ stained with DAPI (nuclear stain; $\mathbf{A}, \mathbf{B}$ ) and fluorescein conjugated wheat germ agglutinin (WGA; sarcolemmal stain; $\mathbf{C , D}$ ). Note the presence of subsarcolemmal and intermyofibrillar myonuclei, as well as the prominent fiber subdivisions indicated by green-fluorescent WGA staining. Scale bar $=200 \mu \mathrm{m}$. 


\section{REFERENCES}

Anderson, D.T. 1993. Barnacles: structure, function, development and evolution, $357 p$.

Anderson, D.T. and A.J. Southward. 1987. Cirral activity of barnacles. In Barnacle Biology (ed. Southward, A.J.), pp. 213-225. Rotterdam, Netherlands: A. A. Balkema.

Barnes, H., D.M. Finlayson, and J. Piatigorsky. 1963. The effect of dessication and anaerobic conditions on the behavior, survival and general metabolism of three common cirripedes. Journal of Animal Ecology. 32(2): 233-252.

Barnes, H., and M. Barnes. 1969. Seasonal changes in the acutely determined oxygen consumption and effect of temperature for three common cirripedes, Balanus balanoides (L.), B. balanus (L.), and Chthamalus stellatus (Poli). Journal of Experimental Marine Biology and Ecology. 4: 36-50.

Bergeron, R., J.M. Ren, K.S. Cadman, I.K. Moore, P. Perret, M. Pypaert, and G.I. Shulman. 2001. Chronic activation of AMP kinase results in NRF-1 activation and mitochondrial biogenesis. American Journal of Physiology, Endocrinology and Metabolism. 281(6): E1340-1346.

Booth, J.H., G.F. Jansz, and G.F. Holeton. 1982. Cl-, K+, and acid-base balance in rainbow trout during exposure to, and recovery from, sublethal environmental acidification. Canadian Journal of Zoology. 60(5): 1123-1130.

Boyle, K.L., R.M. Dillaman, and S.T. Kinsey. 2003. Mitochondrial distribution and glycogen dynamics suggest diffusion constraints in muscle fibers of the blue crab, Callinectes sapidus. Journal of Experimental Zoology. Part A, Comparative Experimental Biology. 297(1): 1-16.

Bridges, C.R., and A.R. Brand. 1980. The effect of hypoxia on oxygen consumptin and blood lactate levels of some marine crustacea. Comparative Biochemistry and Physiology. 65(A): 399-409.

Burke, E. 1979. Aerobic and anaerobic metabolism during hypoxia in two species of intertidal activity crabs'. The Biollogical Bulliton. 156: 157-168.

Burnett, L.E., T.N. Dunn, and R.L. Infantino, Jr. 1985. The Function of Carbonic Anhydrase in Crustacean Gills. Transport processes, iono- and osmoregulation: current comparative approaches: 159-168.

Castro, A.J.M., D.A. López, and M.V. Vial. 2015. Physiological responses to hypoxia and anoxia in Jehlius cirratus (Darwin, 1854) (Cirripedia, Chthamalidae) in the upper intertidal zone. Crustaceana. 74(2): 161-170. 
Cohen, C. 1982. Matching molecules in the catch mechanism. Proceedings of the National Academy of Sciences of the United States of America. 79(10): 3176-3178.

Davenport, J., and S. Irwin. 2003. Hypoxic life of intertidal acorn barnacles. Marine Biology. 143(3): 555-563.

Desai, D.V., and S. Prakash. 2009. Physiological responses to hypoxia and anoxia in Balanus amphitrite. Marine Ecology Progress Series. 390: 157166.

Dissanayake, A., R. Clough, J.I. Spicer, and M.B. Jones. 2010. Effects of hypercapnia on acid-base balance and osmo-/iono-regulation in prawns (Decapoda: Palaemonidae). Aquatic Biology. 11: 27-36.

Egginton, S. 1994. Stress response in two Antarctic teleosts (Notothenia coriiceps Richardson and Chaenocephalus aceratus Lönnberg) following capture and surgery. Journal of Comparative Physiology B. 164(6): 482491.

Galler, S., J. Litzlbauer, M. Kross, and H. Grassberger. 2010. The highly efficient holding function of the mollusc 'catch' muscleis not based on decelerated myosin head cross-bridge cycles. Proceedings of the Royal Society. 277: 803-808.

Gilman, S.E., J.W.H. Wong, and S. Chen. 2013. Oxygen consumption in relation to body size, wave exposure, and cirral beat behavior in the barnacle Balanus glandula. Journal of Crustacean Biology. 33(3): 317-322.

Grantham, B.A., F. Chan, K.J. Nielsen, D.S. Fox, J.A. Barth, A. Huyer, and B.A. Menge. 2004. Upwelling-driven nearshore hypoxia signals ecosystem and oceanographic changes in the northeast Pacific. Nature. 429(6993): 749754.

Gray, J.S., R.S.S. Wu, and Y.Y. Or. 2002. Effects of hypoxia and organic enrichment on the coastal marine environment. Marine Ecology Progress Series. 238: 249-279.

Grieshaber, M.K., I. Hardewig, U. Kreutzer, and H.O. Pörtner. 1994. Physiological and metabolic responses to hypoxia in invertebrates. Reviews of Physiology, Biochemistry and Pharmacology. 125: 43-147.

Guppy, M. .2004. The biochemistry of metabolic depression: a history of perceptions. Comparative Biochemistry and Physiology. Part B: Biochemistry and Molecular Biology. 139(3): 435-442. 
Hardy, K.M., R. M. Dillaman, B.R. Locke, and S.T. Kinsey. 2009. A skeletal muscle model of extreme hypertrophic growth reveals the influence of diffusion on cellular design. American Journal of Physiology. Regulatory, Integrative and Comparative Physiology. 296(6): R1855-R1867.

Hardy, K.M., S.C. Lema, and S.T. Kinsey. 2010. The metabolic demands of swimming behavior influence the evolution of skeletal muscle fiber design in the brachyuran crab family Portunidae. Marine Biology. 157(2): 221-236.

Henry, R.P., C. Luca, H. Onken, and D. Weihrauch. 2012. Multiple functions of the crustacean gill: osmotic/ionic regulation, acid-base balance, ammonia excretion, and bioaccumulation of toxic metals. Frontiers in Physiology. 3 (431): 1-33.

Henry, R.P., and M.G. Wheatly. 1992. Interaction of respiration, ion regulation, and acid-base balance in the everday life of aquatic crustaceans. American Zoologist. 32(3): 407-416.

Holeton, G.F. 1974. Metabolic cold adaptation of polar fish: fact or artefact? Physiological Zoology. 47(3): 137-152.

Hoppeler, H., E. Kleinert, C. Schlegel, H. Claassen, H. Howald, S.R. Kayar, and P. Cerretelli. 1990. II Morphological adaptations of human skeletal muscle to chronic hypoxia. International Journal of Sports Medicine. 11(S1): S3-S9.

Hoyle, G., P.A. McNeill, and A.I Selverston. 1973. Ultrastructure of barnacle giant muscle fibers. The Journal of Cell Biology. 56: 74-91.

Hoyle, G. 1987. The giant muscle cells of barnacles. In Barnacle Biology (ed. Southward, A.J.), pp. 213-225. Rotterdam, Netherlands: A. A. Balkema.

Innes, A.J. 1985. Oxygen uptake and haemolymph oxygen tension in the stalked barnacle Calantica spinosa. New Zealand Journal of Zoology. 12: 111-117.

Jahromi, S.S., and H.L. Atwood. 1971. Structural and contractile properties of lobster leg-muscle fibers. Journal of Experimental Zoology. 176(4): 475-486.

Jensen, F.B. 1990. Sublethal physiological changes in freshwater crayfish, Astacus astacus, exposed to nitrite: haemolymph and muscle tissue electrolyte status, and haemolymph acid-base balance and gas transport. Aquatic Toxicology. 18: 51-60.

Jimenez, A.G., S.K. Dasika, B.R. Locke, and S.T. Kinsey. 2011. An evaluation of muscle maintenance costs during fiber hypertrophy in the lobster, Homarus americanus. Are larger muscle fibers cheaper to maintain? Journal of Experimental Biology. 214(21): 3688-3697. 
Jimenez, A. G., Locke, B. R., \& Kinsey, S. T. (2008). The influence of oxygen and high-energy phosphate diffusion on metabolic scaling in three species of tail-flipping crustaceans. The Journal of Experimental Biology, 211(20), 3214 LP-3225.

Jimenez, A.G., S.T. Kinsey, R.M. Dillaman, and D.F. Kapraun. 2010. Nuclear DNA content variation associated with muscle fiber hypertrophic growth in decapod crustaceans. Genome. 53: 161-171.

Jimenez, A.G., and S.T. Kinsey. 2012. Nuclear DNA content variation associated with muscle fiber hypertrophic growth in fishes. Journal of Comparative Physiology B. 182: 531-540.

Johnson, L.K., R. M. Dillaman, D.M. Gay, J.E. Blum, and S.T. Kinsey. 2004. Metabolic influences of fiber size in aerobic and anaerobic locomotor muscles of the blue crab, Callinectes sapidus. The Journal of Experimental Biology. 207(23): 4045-4056.

Johnston, I.A., and L.M. Bernard. 1982. Ultrastructure and metabolism of skeletal muscle fibres in the tench: Effects of long-term acclimation to hypoxia. Cell and Tissue Research. 227(1): 179-199.

Kinsey, S.T., K.M. Hardy, and B.R. Locke. 2007. The long and winding road: influences of intracellular metabolite diffusion on cellular organization and metabolism in skeletal muscle. Journal of Experimental Biology, 210(20): 3505-3512.

Kinsey, S.T., B.R. Locke, and R.M. Dillaman. 2011. Molecules in motion: influences of diffusion on metabolic structure and function in skeletal muscle. The Journal of Experimental Biology. 214(2): 263-274.

Kinsey, S.T., P. Pathi, K.M. Hardy, A. Jordan, and B.R. Locke. 2005. Does intracellular metabolite diffusion limit post-contractile recovery in burst locomotor muscle? The Journal of Experimental Biology. 208(14): 26412652.

Lieber R.L. 2002. Skeletal muscle structure, function and plasticity, 336p.

Locke, B.R., and S.T. Kinsey. 2008. Diffusional constraints on energy metabolism in skeletal muscle. Journal of Theoretical Biology. 254(2): 417429.

López, A.D.A, J.M. Castro, M.L. González, R.W. Simpfendörfer, S. Crustaceana, N. May, and M.L.G. Lez. 2003. Physiological responses to hypoxia and anoxia in the giant barnacle, Austromegabalanus psittacus (Molina, 1782). Crustaceana. 76(5): 533-545. 
McDonald, D.G., H. Hobe, and C.M. Wood. 1980. The influence of calcium on the physiological responses of the rainbow trout, Salmo gairdneri, to low environmental $\mathrm{pH}$. Journal of Experimental Biology. 88: 109-131.

Murdoch, R.C., and S.E. Shumway. 1980. Oxygen consumption in six species of chitons in relation to their position on the shore. Ophelia. 19(2): 127-144.

Mykles, D.L. 1997. Crustacean muscle plasticity: molecular mechanisms determining mass and contractile properties. Comparative Biochemistry and Physiology Part B: Biochemistry and Molecular Biology. 117(3): 367-378.

Newell, R., and H. Northcroft. 1965. The relationship between cirral activity and oxygen uptake in Balanus balanoides. Journal of Marine Biological Association UK. 45: 387-403.

Ocampo, L., D. Patiño, and C. Ramírez. 2003. Effect of temperature on hemolymph lactate and glucose concentrations in spiny lobster Panulirus interruptus during progressive hypoxia. Journal of Experimental Marine Biology and Ecology. 296: 71-77.

Peachey, L.D. 1967. Membrane systems of crab fibers. American Zoologist. 7(3): 505-513.

Petersen, J.A., H.J. Fyhn, and K. Johansen. 1974. Eco-Physiological studies of an intertidal crustacean, Pollicipes polymerus (Cirripedia, Lepadomorpha): aquatic and aerial respiration. Journal of Experimental Biology. 61(1972): 309-320.

Pritchard, A.W., and S. Eddy. 1979. Lactate formation in Callianassa californiensis and Upogobia pugettensis (Crustacea: Thalassinidea) ${ }^{*}$. Marine Biology. 50: 249-253.

Reipschläger, A., and H.O. Pörtner. 1996. Metabolic depression during environmental stress: the role of extracellular versus intracellular $\mathrm{pH}$ in Sipunculus nudus. The Journal of Experimental Biology. 199(8): 1801-1807.

Rosser, B.W., M.S. Dean, and E. Bandman. 2003. Myonuclear domain size varies along the lengths of maturing skeletal muscle fibers. International Journal of Developmental Biology. 46(5): 747-754.

Schmalbruch, H., and U. Hellhammer. 1977. The number of nuclei in adult rat muscles with special reference to satellite cells. The Anatomical Record. 189(2): 169-175.

Selverston, A. 1967. Structure and function of the transverse tubular system in crustacean muscle fibers. American Zoologist. 7(3): 515-525. 
Spicer, J.I., A. Raffo, and S. Widdicombe. 2007. Influence of $\mathrm{CO}_{2}$-related seawater acidification on extracellular acid-base balance in the velvet swimming crab Necora puber. Marine Biology. 151: 1117-1125.

Spicer, J.I. 2014. What can an ecophysiological approach tell us about the physiological responses of marine invertebrates to hypoxia? Journal of Experimental Biology. 217(1): 46-56.

Taylor, E.W. 1981. Some effects of temperature on respiration in decapodan crustaceans. Journal of Thermal Biology. 6(9): 239-248.

Taylor, E.W., and N.M. Whiteley. 1989. Oxygen transport and acid-base balance in the haemolymph of the lobster, Homarus gammarus, during aerial exposure and resubmersion. Journal of Experimental Biology. 144: 417-436.

Terwilliger, N.B., and M. Ryan. 2001. Ontogeny of crustacean respiratory proteins. American Zoologist. 41(5): 1057-1067.

Vial, M.V., D.A. Lopez, and M.L. Gonzalez. 1999. Responses to environmental hypoxia of balanomorph barnacles. Barnacles. The biofoulers: 215-244.

Waite, M.E., and G. Walker. 1988. The haemocytes of balanomorph barnacles. Journal of the Marine Biological Association of the United Kingdom. 68(3): 391-397.

Walsh, P.J., and R.P. Henry. 1990. Activities of metabolic enzymes in the deepwater crabs Chaceon fenneri and C. quinquedens and the shallow-water crab Callinectes sapidus. Marine Biology. 106(3): 343-346.

Weatherly, A.H., and H.S. Gill. 1987. Fish growth in marine culture systems: a challenge for biotechnology. Journal of Marine Biotechnology. 1(4): 376-379.

Weber, R.E., J.W. Behrens, H. Malte, and A. Fago. 2008. Thermodynamics of oxygenation-linked proton and lactate binding govern the temperature sensitivity of $\mathrm{O} 2$ binding in crustacean (Carcinus maenas) hemocyanin. Journal of Experimental Biology. 211: 1057-1062. 